ENGINEERING CHANGE NOTICE

........

Proj. $<-25 \gamma-\operatorname{coc} 6$

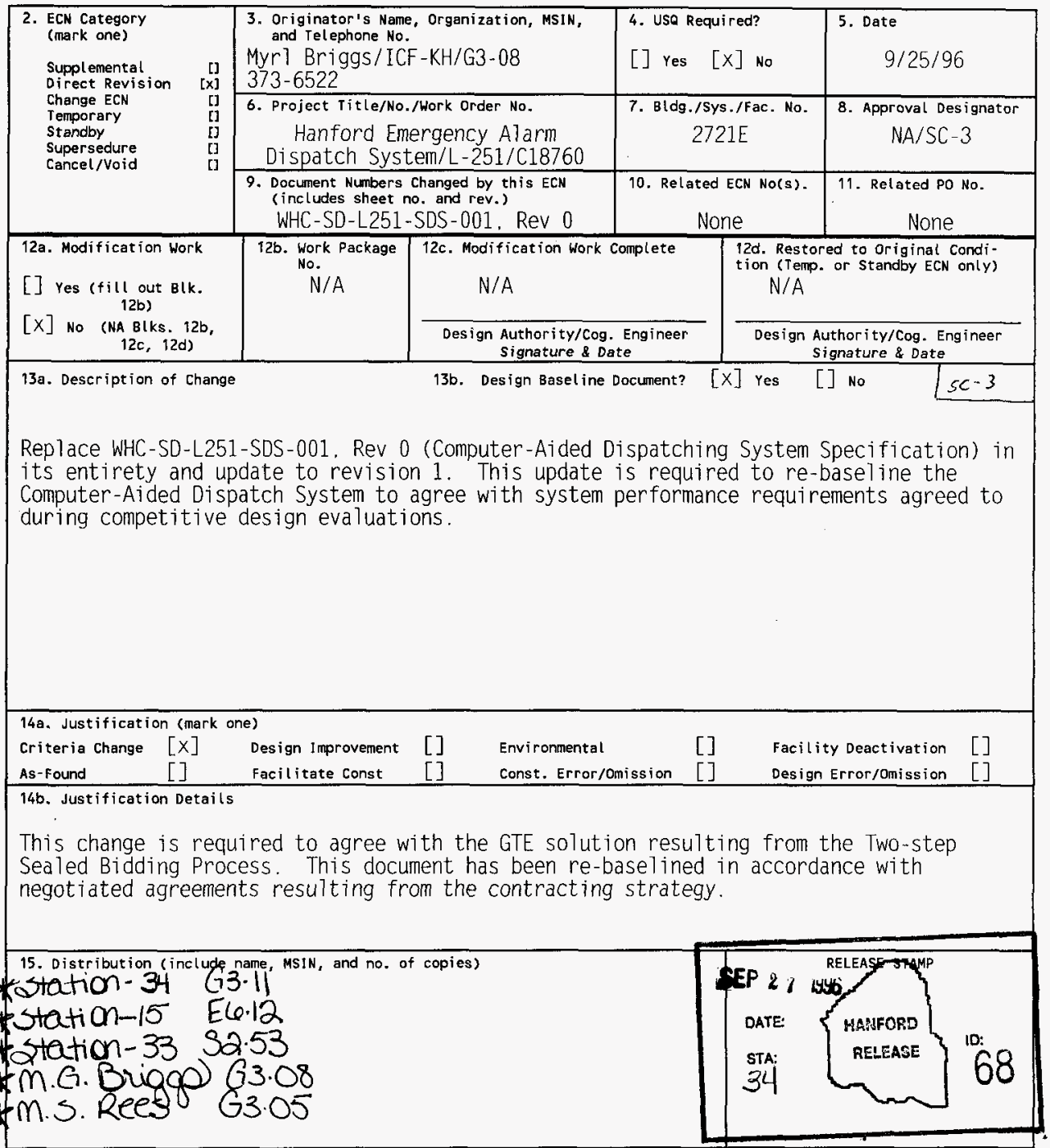

A-7900-013-2 (05/96) GEF095

* = Adranced 


\section{Computer-Aided Dispatching System Design Specification}

Myrl Briggs

ICF-KH, Richland, WA 99352

U.S. Department of Energy Contract DE-AC06-87RL10930

$\begin{array}{llll}\text { EDT/ECN: } & L-251-006 & \text { UC: } 607 \\ \text { Org Code: } & 5 \text { C100 } & \text { Charge Code: } & \text { P2Y700 } \\ \text { B\&R Code: } & 35 E W 70300 & \text { Total Pages: } 67\end{array}$

Key Words: Computer-Aided Dispatching System Design Specification, L251. Hanford Emergency Alarm Dispatching System

Abstract: This document defines the performance requirements for $a$ graphic display dispatching system to support Hanford Patrol emergency response. This document out 7 ines the negotiated requirements as agreed to by GTE Northwest during technical contract discussions. This systern defines a commercial off-the-shelf computer dispatching system providing both test and graphic display information while interfacing with diverse alarm reporting system within the Hanford Site. This system provided expansion capability to integrate Hanford Fire and the Occurrence Notification Center. The system also provided back-up capability for the Plutonium Processing Facility (PFP).

TRADEMARK DISCLAIMER. Reference herein to any specific comnercial product, process, or service by trade name, trademark, manufacturer, or otherwise, does not necessarily constitute or imply its endorsement, recommendation, or favoring by the United States Government or any agency thereof or its contractors or subcontractors.

Printed in the United States of America. To obtain copies of this document, contact: WHC/BCS Document Control Services, P.O. Box 1970, Mailstop H6-08, Richland WA 99352, Phone (509) 372-2420; Fax (509) 376-4989.
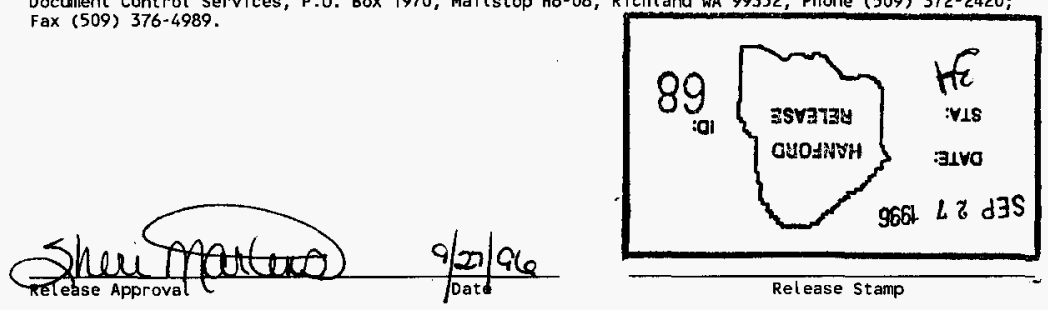

\section{Approved for Public Release}


WHC-SD-L251-SDS-001

Rev. 1

PROJECT L-251

HANFORD EMERGENCY ALARM DISPATCH SYSTEM (HEADS)

200 East Area, Hanford, Washington

FOR

ICF KAISER HANFORD COMPANY

P. O. Box 888

Richland, Washington 99352

\section{COMPUTER-AIDED DISPATCHING SYSTEM SPECIFICATION}

By:

SCM CONSULTANTS, INC.

7601 West Clearwater Avenue \#301

Kennewick, Washington 99336

As Amended By:

GTE NORHTWEST 


\section{RECORD OF REVISION}

(2) Title

Computer-Aided Dispatching System Design Specification

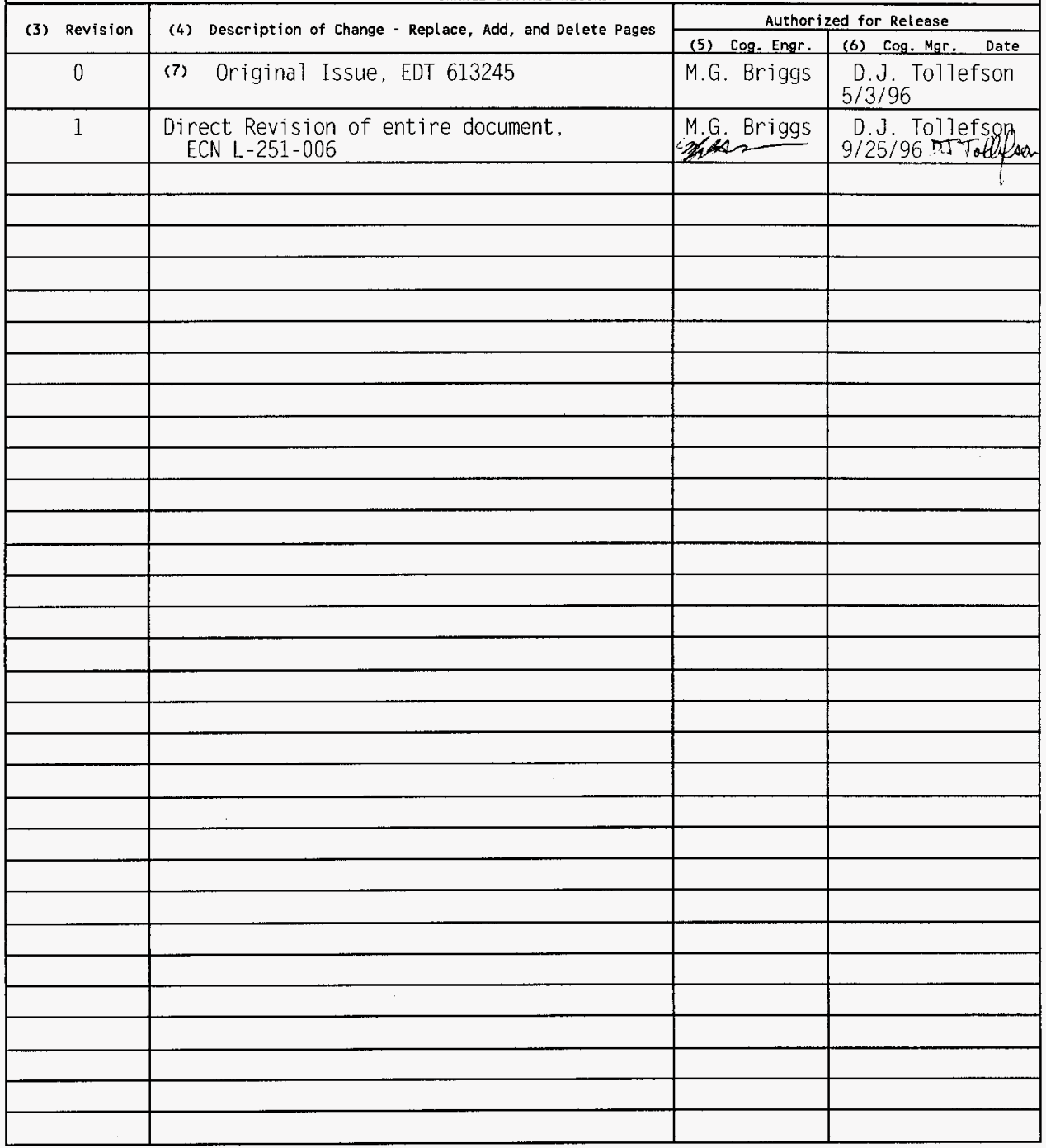




\section{COMPUTER-AIDED DISPATCHING SYSTEM SPECIFICATION}

FOR

\section{HANFORD EMERGENCY ALARM DISPATCH SYSTEM}

PROJECT L-251

\section{TASK ORDER KH-8010A-22, APPENDIX V}

Prepared By:
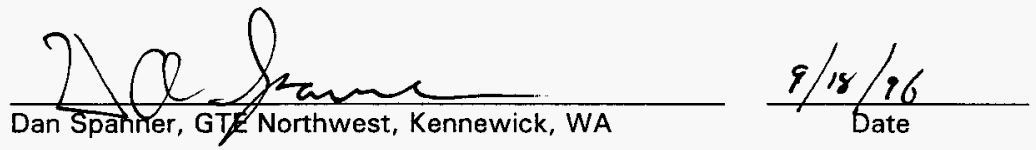

Approved By:

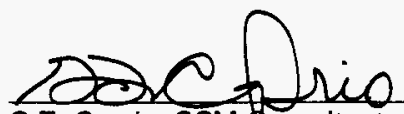

G.T. Caprio, SCM Gonsultants, Kennewick, WA
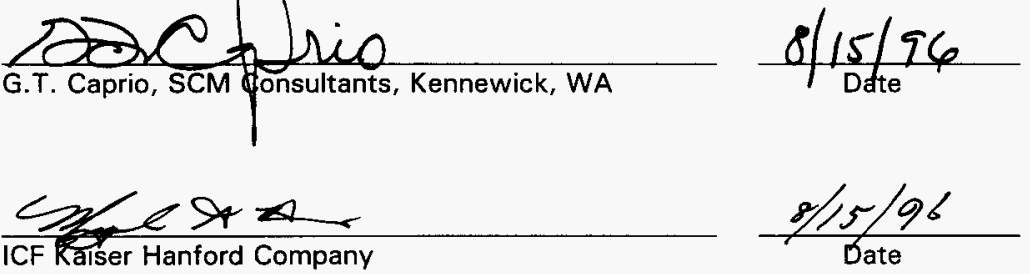


\section{TECHNICAL SPECIFICATION}

\section{TABLE OF CONTENTS}

A

1.0

2.0

3.0

3.1

3.1.1

3.1 .2

3.1 .3

3.1 .4

3.1 .5

3.1.6

3.1 .7

3.2

3.2.1

3.2 .2

3.2.3

3.2.3.1

3.2.3.2

3.2.3.3

3.2.3.4

3.2.3.5

3.2.3.6

3.2 .4

3.2 .5

3.2 .6

3.2.7

3.2 .8

3.2 .9

3.2.9.1

3.2.9.2

3.2 .10

3.2 .11

3.2 .12

3.2 .13
Acronyms/Abbreviations

Scope

Applicable Documents

System Configuration

General .

Electrical

Environment

Dispatch Station Identification and Marking

Wiring and Connectors

Performance

Document Identification Requirements

Acceptance

System Hardware

CAD System

CAD Stations

CAD Station Components

CAD Computer .....

Monitor....

Functional Keyboard

Radio/Telephone Switching Panel

CAD Station Consoles and Chairs

CAD System Assembly

Server (Central Processing Unit)

HLAN Computer

Disk Storage....

Magnetic Tape Subsystem Storage

CD Recorder

Printers

High-Speed Event Printer

Laser Printer

Audio Tape Recording

General information.

Hardware Maintainability

Redundancy 


\section{TABLE OF CONTENTS (Continued)}

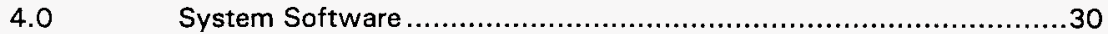

4.1 General Requirements....................................................... 30

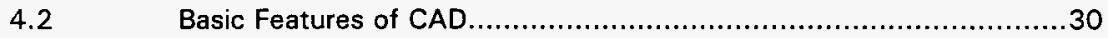

$4.3 \quad$ Specific System Requirements ...............................................

Call Taker Functionality ....................................................... 34

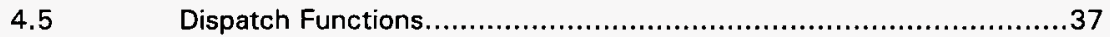

4.6 Status Monitoring ............................................................... 42

4.7 Management Reports .................................................43

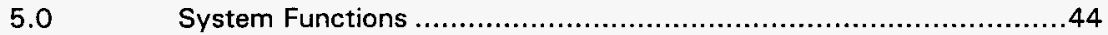

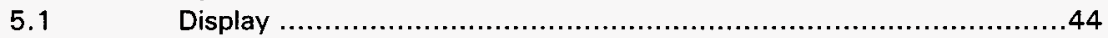

$5.2 \quad$ Group Display .................................................................. 45

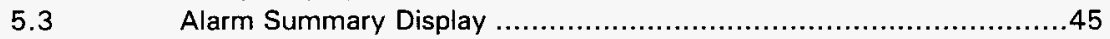

5.4 Alarm Annunciation................................................................

$5.5 \quad$ Alarm Acknowledgement and Clearing ....................................46

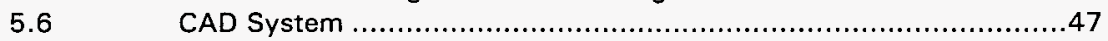

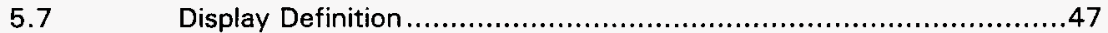

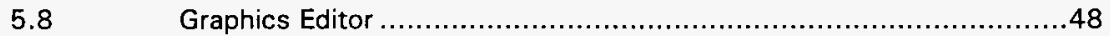

$5.9 \quad$ Configuration Documentation ............................................ 48

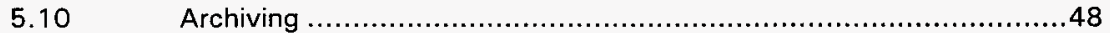

$5.11 \quad$ Display Selection ........................................................ 49

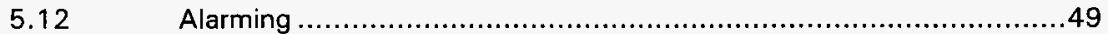

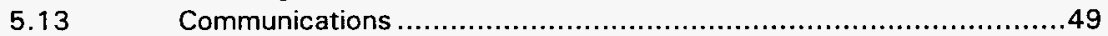

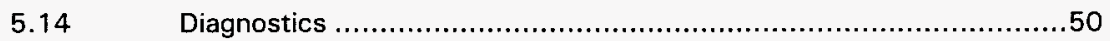

6.0 System Interface and Functions......................................50

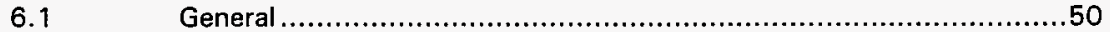

6.2 Patrol Alarm Operations ....................................................... 51

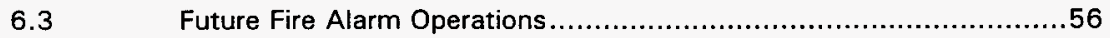

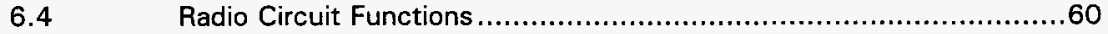

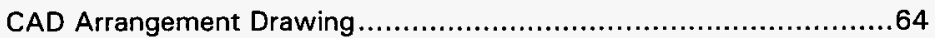


WHC-SD-L251-SDS-001

Rev. 1

Page 3

\section{ABBREVIATIONS/ACRONYMS}

The following is a list of abbreviations and acronyms used within this document.

$\begin{array}{lll}\text { AC } & - & \text { Alternating Current } \\ \text { ALI } & - & \text { Automatic Location Information } \\ \text { AMP } & - & \text { Amperes } \\ \text { ANI } & - & \text { Automatic Number Identification } \\ \text { AP } & - & \text { Alarm Processor } \\ \text { ATP } & - & \text { Acceptance Test Procedure } \\ \text { bPS } & - & \text { bits per second } \\ \text { CAD } & - & \text { Computer Aided Dispatching } \\ \text { CD } & - & \text { Compact Disk } \\ \text { CFS } & - & \text { Central Fire Station } \\ \text { CLID } & - & \text { Calling Line Identification Directory Member } \\ \text { CRT } & - & \text { Cathode Ray Tube } \\ \text { CSA } & - & \text { Canadian Standard Association } \\ \text { dB } & - & \text { Decibel } \\ \text { dBM } & - & \text { Decibels of Power Reference to 1 Milliwatt } \\ \text { DC } & - & \text { Direct Current } \\ \text { DTMF } & - & \text { Dial Tone Multi-Frequency } \\ \text { EMS } & - & \text { Emergency Medical Service } \\ \text { ENS } & - & \text { Emergency Notification System } \\ \text { ESS } & - & \text { Electronic Switching System } \\ \text { FCC } & - & \text { Federal Communication Commission } \\ \text { FM } & - & \text { Factory Mutual } \\ \text { FSK } & - & \text { Frequency Shift Keying } \\ \text { HLAN } & - & \text { Hanford Local Area Network } \\ \text { HZ } & - & \text { Hertz } \\ \text { ID } & - & \text { Identification } \\ \text { I/O } & - & \text { Input/Output } \\ \text { KHz } & - & \text { Kilo Hertz } \\ \text { LED } & - & \text { Light Emitting Diode } \\ \text { Mb } & - & \text { Megabytes } \\ \text { MDT } & - & \text { Mobile Display Terminal } \\ \text { MIL-STD } & - & \text { Military Standard } \\ \text { ma } & - & \text { Milli Amperes } \\ \text { ms } & - & \text { milli Second } \\ \text { MUX } & - & \text { Multiplexer } \\ \text { NEC } & - & \text { National Electrical Code } \\ \text { NEMA } & - & \text { National Electrical Manufacturer's Association } \\ \text { NFPA } & - & \text { National Fire Protection Association } \\ & & \end{array}$


WHC-SD-L251-SDS-001

Rev. 1

Page 4

ABBREVIATIONS/ACRONYMS (cont'd)

$\begin{array}{lll}\text { PFP } & - & \text { Plutonium Finishing Plant } \\ \text { POC } & - & \text { Patrol Operations Center } \\ \text { PSK } & - & \text { Phase Shift Keying } \\ \text { PTT } & - & \text { Push To Talk } \\ \text { RAM } & - & \text { Random Access Memory } \\ \text { RCL } & - & \text { ReCaLI } \\ \text { RFAR } & - & \text { Radio Fire Alarm Reporting } \\ \text { ROM } & - & \text { Read Only Memory } \\ \text { SOPs } & - & \text { Standard Operating Procedures } \\ \text { TDD } & - & \text { Telephone Device for Deaf and Hearing Impaired } \\ \text { UL } & - & \text { Underwriter's Laboratory } \\ \text { VAC } & - & \text { Volts, Alternating Current }\end{array}$


Rev. 1

Page 5

\subsection{SCOPE}

$1.1 \quad$ This specification establishes the requirements for an Emergency Alarm Dispatch System that will be furnished and installed in the Patrol Operations Center located in Room 08, 08A and 11 of the 2721E Building in the 200 East Area on the Hanford Reservation in Richland, Washington.

1.1.1 It will be a fully integrated, multi-element communications system comprised of radio/telephone systems, a computer aided dispatch system, alarm receiving systems, and radio/telephone switching systems. Section 6 describes the radio/telephone interface requirements. It will have the hardware capability to add the fire alarm reporting system at a later date without the need to replace any significant component of the system. The operator consoles and servers should be of sufficient capability that they will not need to be replaced if the full fire dispatch capability is added in the future.

1.1.2 It will provide for one main dispatch center consisting of four dispatch stations with one dispatch station designated for supervision and training. The supervisor's console will have the capability to configure the functions at the other consoles.

1.1.3 GTE will provide the capability to interface with the currently identified circuits plus provide $20 \%$ growth capability without degraded performance. The current circuit interface consists of 500 local/ industrial security sensors (See Section 6.2.10.1), 500 fire alarm (RS232) inputs, and 400 event blocks (RS232) from PFP. In addition, the system will have the capability to expand to include 10,000 fire alarm inputs. It will provide the capability to expand to meet new demands placed on it by growth. (See Section 6.2.10 for description of present inputs.)

1.1.4 It will provide the capability to dispatch patrol, fire, emergency medical, and sheriff services.

1.1.5 It will provide the capability to display ALI and ANI information.

1.1.6 GTE will provide the capability for an interface to existing alarm systems to automatically generate an event alarm upon detection of an intrusion, fire, panic, or specified environmental condition through the inclusion of an independent Alarm Processor (AP). The future interface to the RFAR system will be accomplished without 
WHC-SD-L251-SDS-001

Rev. 1

Page 6

jeopardizing a Factory Mutual approval. It will be capable of meeting the requirements of a Class $1 \mathrm{CAD}$ system as specified in the present NFPA 1221, Section 3-12.

1.1.7 The Vision CAD system has the interface to allow for incident reporting from a mobile $P C$ and provides standard interfaces that would allow for on site incident reporting and forms to be electronically captured and forwarded.

1.1.8 The ENS system is no longer a requirement for this response. The basic telephony technology required to perform this function is part of our core business. We would appreciate an opportunity to compete on this business at a future time.

1.1.9 It will provide the capability to interface with a telephone device for the deaf and hearing impaired Callers (TDD).

1.1.10 GTE will interface with all incoming signals and required databases via an AP independent of the CAD system but will communicate to the front end controller and will be integrated into the CAD.

1.1.11 Recording

1.1.11.1 Emergency calls (radio and telephone) and alarms will be automatically recorded and the recording equipment will be provided with instant playback capability.

1.1.11.2 Alarm records will be printed out on high-speed printers.

1.1.11.3 Slow-speed printers will be utilized to print records, reports, and any other printing requirements, including selectable output from the HLAN system.

1.1.12 Upon receipt of an alarm, the time and date will be automatically recorded to both a hard disk and to a high speed printer.

1.2 The dispatch system will function as follows:

1.2.1 The computer-aided dispatching server will be a redundant system. The secondary server will be "hot stand-by" that will be switched online in the event the primary server fails. Both servers will share a mirrored database on redundant drives. 
WHC-SD-L251-SDS-001

Rev. 1

Page 7

\subsubsection{Annunciate Alarms}

1.2.2.1 An audible tone will be used to notify the operator when an alarm is received by the system. A different tone will be used to differentiate between PFP secondary annunciations, local/industrial security alarms, and future fire alarms.

\subsubsection{Display Alarms}

1.2.3.1 Critical information will be graphically displayed to the operator for appropriate actions.

1.2.3.2 The information will be presented in the following forms:

1.2.3.2.1 Display of alarm information (type, location, conditions).

1.2.3.2.2 Special instructions, such as hazards and exposures, are provided for critical areas.

1.2.3.2.3 The potential for future decoded fire and trouble alarms will be processed through the AP. (This is the standard G. H. Harlow Company RFAR interface, see Section 6.3.)

\subsubsection{Log Alarms}

1.2.4.1 System activities are logged to a hard copy device and to disk file(s) for historical reference. The information logged includes, but is not restricted to, the following:

1.2.4.1.1

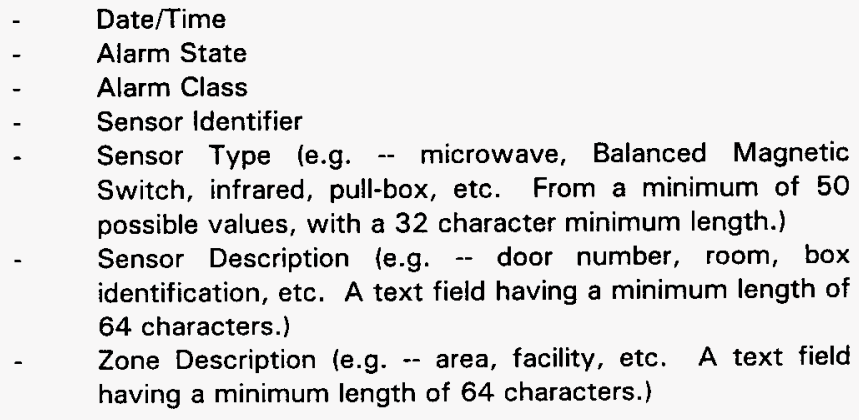


WHC-SD-L251-SDS-001

Rev. 1

Page 8

1.2.4.1.2 Operator Actions (e.g. -- Transactions made to: log on/off system; acknowledge, assess, and dispose of the alarms; change operational mode of sensors between active, access, and inactive/maintenance; etc.)

1.2.4.2 Alarms in by-pass and alarm status will be logged and available for recall through the Ap supervisor.

1.2.5 Archival Storage (System Activity)

1.2.5.1 System activities will be logged to disk and disk files as activity occurs. Disk storage is transferred to removable media (tape storage) on a periodic basis for analysis and long-term storage.

NOTE: Archival files in the AP will contain all alarm activity information.

1.2.6 Network Status. The system will monitor the health of the network communications and the connected systems.

1.2.6.1 Network Health Display

1.2.6.1.1 Symbols represent connected systems

1.2.6.1.2 Symbol colors represent operational status foperational, standby, inoperable).

2.0

\section{APPLICABLE DOCUMENTS}

NFPA 1221,1994

MIL-STD-1472D

NFPA 70 (NEC) 1996

3.0

SYSTEM CONFIGURATION

3.1

General

3.1.1

Electrical

3.1.1.1 The CAD communication and companion equipment will operate on single phase 120 volt $(+5,-15$ volts) $A C$ at 60 Hertz $( \pm 1$ Hertz). 
WHC-SD-L251-SDS-001

Rev. 1

Page 9

3.1.1.2 All $A C$ power wiring and grounding of the CAD equipment will be designed in accordance with the NEC.

3.1.1.2.1 All console equipment power cords will be sufficient length and have a locking cap (NEMA L5-2OP). (Reference Drawing H-2-825033)

3.1.1.3 The Seller will submit a summary of the power requirements for each piece of equipment prior to furnishing the equipment.

3.1.1.4 All AC electrical equipment provided as part of the CAD will be listed by a nationally recognized agency such as the Underwriter's Laboratory (UL), the Factory Mutual (FM), or the Canadian Standard Association (CSA).

3.1.1.5 All electronic equipment will be fully solid-state and will reflect the latest advances in the state-of-the-art. All equipment and material will be new.

\subsubsection{Environment}

3.1.2.1 The normal operating environment for the dispatch stations will be 65 to $80^{\circ} \mathrm{F}$, however, the dispatch stations will be rated for continuous operation over a temperature range of 50 to $104^{\circ} \mathrm{F}$ within a relative humidity range of $20 \%$ to $80 \%$ non-condensing.

Dispatch Station Identification and Marking.

3.1.3.1 Each dispatch station will be permanently labeled with a unique identification number.

3.1.3.2 All major sub-assemblies and printed circuit boards will be clearly identified and permanently marked with Seller's normal part numbering scheme.

3.1.4 Wiring and Connectors

3.1.4.1 The Seller will provide and install all interconnecting wire and cables required between system cabinets, assemblies, and sub-assemblies.

3.1.4.2 All connectors will be secured to their respective sockets by mechanical means, (e.g., clips, screws, etc.). 
WHC-SD-L251-SDS-001

Rev. 1

Page 10

3.1.4.3 Connectors used for high impedance, low current circuits will have gold-plated contacts as applicable.

3.1.4.4 All cables and wiring between sub-systems will be clearly and permanently labeled. Labeling will correspond to the wiring designations on the Seller's drawings and schematics.

3.1.4.5 Wiring diagrams showing all cables, wiring, and wiring terminations will be provided.

3.1.4.6 The wiring diagram will delineate the termination points for the Buyer Representative's field devices and provide space for the Buyer Representative to label each aisle point with the Buyer Representative's field instrumentation tag numbers.

\subsubsection{Performance}

3.1.5.1 The CAD stations via the AP will be capable of receiving all designated alarm points which include contact closures, serial data streams, telephone contacts, and radio contacts (See Section 6.2.10 for POC alarms and 6.3 for future RFAR alarms). It will record all alarm and other transactions. It will be capable of dispatching by voice.

3.1.5.2 The AP will be capable of monitoring, arbitrating, and updating all alarm points at a rate .085 seconds.

3.1.5.3 The AP will be capable of monitoring, arbitrating, and updating all alarm status points at least one per second.

3.1.5.4 Dynamic information on displays will be updated with new information from the server at least once every three seconds, assuming any exceptions in reporting criteria has been met.

3.1.5.5 Alarms will be communicated from the AP to the CAD within one second of sensing at the server input.

3.1.5.6 The AP supervisor will determine the priority of the alarms, receive and queue the alarms in order of priority and communicate the information, coded, to the CAD.

3.1.5.7 Graphic display call-up of alarm status at the AP supervisor will not require more than two seconds. 
WHC-SD-L251-SDS-001

Rev. 1

Page 11

3.1.5.8 The high-speed printer will produce a copy of an alarm received within two seconds.

3.1.6 Document Identification Requirements.

3.1.6.1 All documentation will be identified with a certified vendor information number. The number and format will be furnished by the Buyer.

3.1.6.1.1 The identification number will be permanently located on the cover and the first page of all documents.

3.1.6.1.2 All documentation will be identified with a descriptive title. This title will uniquely identify the information contained within the document.

3.1.6.2 Technical Manuals and Drawings.

3.1.6.2.1 All technical manuals developed for this system will be standard 8 $1 / 2 " \times 11$ " with the exception of drawings and foldouts which should be $11^{\prime \prime} \times 17^{\prime \prime}$. Existing manuals may be expected in current format upon approval by the Buyer.

3.1.6.2.2 Electronic "Help" files and system documentation that are standard offerings from our Strategic Partners will be available in an industry standard format.

\subsubsection{Hardware Documentation.}

3.1.6.3.1 Dimensional drawings illustrating all major components of the CAD system will be provided showing detailed information on system construction. This information will clearly identify the component size and assembly.

3.1.6.3.2 Hardware manuals will be provided for all equiment and will include description, maintenance and servicing instructions, schematic diagrams and complete illustrative parts breakdown including a unique description of all parts for easy identification.

3.1.6.3.3 Maintenance manuals will contain detailed description to the board level of the equipment. The manual will contain information required to troubleshoot the system to isolate problems to a board level. It will include detailed operation and performance measurement information. The manual will contain description, performance specifications, block diagrams, circuit diagrams, component locators and description of all 
option jumpers and switch charts. It will be possible to isolate a system fault to the board level through use of this manual.

\subsubsection{Operating System Manual}

3.1.6.4.1 Operating System manuals will be provided for the programming language compiler, the operating system, computer operating software, installation and system debugging. This will contain all the necessary information to troubleshoot and isolate operating system faults for identification.

\subsubsection{CAD Operating Manuals}

3.1.6.5.1 An operating manual will be provided that demonstrates how to use the CAD system and to assist the operators in using the system. This manual will have a look-up table so an operator can find "how to instructions" to common operator questions. This look-up table will be listed by easily identifiable phrases and questions.

3.1.6.5.2 This operating manual will identify how to use the CAD system from system log-on through all areas of operation.

3.1.6.6 CAD Configuration Manual

3.1.6.6.1 A configuration manual will be provided that delineates the method required to configure the system and assign users. This manual will identify the supervisor control and monitor capability. It will also include the instructions on how to configure and use the supervisor's console as a training console.

\subsubsection{Acceptance}

3.1.7.1 Factory acceptance will be performed at the mock installation site in Kennewick, Washington, and final acceptance at the site by the Buyer. 
3.1.7.2 All components will be "integrated" in Kennewick, Washington, prior to delivery and installation at the Hanford POC. A mock installation environment will be established at the Kennewick location to verify system functionality. System inputs will be emulated or installed to achieve effective system verification. A system review by the Buyers/users will be available at multiple times during this phase of the project.

3.1.7.3 Site acceptance will occur in two phases; hardware defivery and final acceptance. Final acceptance will be after all systems have been brought on line and the system is operating as defined in this document. The Seller will provide an integrator (GTE) representative at the site for the duration of the final acceptance period. All acceptance criteria will be mutually agreed after contract award

3.1.7.4 A hardware delivery acceptance document will be signed by the Buyer when all hardware is physically installed. It is not essential that all equipment operate properly at this time. This acceptance is primarily to verify physical presence of all system equipment purchased.

3.1.7.5 The Seller will be provided with a security Acceptance Test Procedure (ATP) developed by the Buyer and agreed upon by the Seller. The security ATP will be approved by the Buyer following successful operational testing of equipment and systems.

3.1.7.6 All peripheral equipment will be tested individually for proper integration and operation. Only one CAD console will be tested for integration and operation at a time. When all CAD consoles and peripheral equipment have been tested and accepted, the CAD system will be brought on line. Only two CAD consoles and one each of the redundant peripheral equipment can be powered up and brought on line prior to disconnection of the existing POC equiment in Room 22. This requirement is necessary so as not to exceed the power capabilities of the existing Uninterruptible Power Supply. The Seller will work closely with the Buyer to verify that the transition from the existing CAD operation to the new CAD oepration has minimum down time.

3.2 System Hardware

3.2.1 CAD System

The CAD system will consist of four CAD dispatching stations working with the server. Three stations will be dispatch stations with the 
Rev. 1

Page 14

fourth station designated as a supervisor station. The supervisor station will be capable of performing the same functions as the other three. It will also be used for instructional purposes, and control configuration. The CAD stations will consist of a dual-screen color display monitor, computer, and keyboard with track ball designed for dispatch operations. The CAD station will also have a centrally located radio/telephone switching panel. The $C A D$ station will combine special hardware and software integrating interactive mapping with dispatching and monitoring functions. Each CAD station will have access to the HLAN system consisting of a computer, keyboard, and monitor separate from with the CAD system. HLAN is located in the right section of the console.

3.2.1.2 The CAD system will be used as a decision support tool. The CAD station will integrate an interactive map display with the functions necessary to capture information recejved through emergency calls.

3.2.1.3 The CAD station will dispatch and monitor service units, incident event status, and control the operations of emergency service vehicles.

\subsubsection{CAD Stations}

\subsubsection{Dispatch CAD Station}

3.2.2.1.1 Each dispatch CAD station will consist of the following:

1. One or more computers.

2. Two 19-inch color CRTs.

3. One function oriented keyboard with track ball.

4. One radio/telephone switching panel.

5. Two 17-inch or two 20-inch quad-split video monitors will be installed above or to the left of the CAD displays. Video input to these monitors will employ manual switching of video selection and destination.

\subsubsection{Supervisor's Console}


WHC-SD-L251-SDS-001

Rev. 1

Page 15

3.2.2.2.1 One supervisor's console configured to see over the console in a sitting position.

\subsubsection{CAD Station Components}

\subsubsection{CAD Computer}

3.2.3.1.1 The computer will utilize a centralized database architecture to provide ease of database maintenance with multiple data bases.

3.2.3.2 Monitor

3.2.3.2.1 All CRTs will be color and have a diagonal measurement of not less than 19 inches.

3.2.3.2.2 The CRT resolution will be at least 1024 pixels horizontal by 768 pixels vertical and be sufficient to provide a clear, sharp display when used with the video generator format as specified.

3.2.3.2.3 The CRTs will have a non-interlaced screen.

3.2.3.2.4 The CRTs will have an anti-static glare guard.

3.2.3.2.5 The video generator will provide a minimum of 256 colors, including black and white.

3.2.3.2.6 The video generator will produce a text format of 40 lines by 80 characters minimum.

3.2.3.2.7 Adjustments for intensity and contrast will be provided.

3.2.3.3 Functional Keyboard

3.2.3.3.1 Each CAD station will have a compatible full function keyboard which is designed for CAD usage.

3.2.3.3.2 Keys will be clearly and permanently labeled as to specific function.

3.2.3.3.3 Labels will be impervious to normal wear and usage for the expected life of the keyboard.

3.2.3.3.4 Industrial hardened keyboards will be provided at each console position. 
WHC-SD-L251-SDS-001

Rev. 1

Page 16

3.2.3.3.5 Audible or tactile feedback will be provided.

3.2.3.3.6 Dedicated and clearly labeled keys will exist for the following functions:

1. Call of all displays.

2. Alarm acknowledgement.

3. Entering the digit $0-9$, sign $(+/-)$, and decimal points.

3.2.3.3.7 A track ball and mouse will be provided for screen pointing, selectable by the operator.

3.2.3.4 Radio/Telephone Switching Panel

3.2.3.4.1 The radio/telephone switching panel will consist of fully distributed switching modules, interface modules to external circuits, speaker(s), microphone, and handset with earphones and microphone.

3.2.3.4.2 The switching panel will facilitate communications between console operators, radio channels and telephone lines.

3.2.3.4.3 The switching panel will be entirely modular and configurable. It will include control modules consisting of a minimum of sixty (60) pushbutton and LED indicators to provide user-friendly controls and indicators designed for a high degree of operational ease and ergonomics.

3.2.3.4.4 Switching panel will utilize tactile line buttons. Each line button will have a removable lens cap that can be engraved with a customer defined identification of up to two lines of six characters per line. Lens caps should be available in up to six colors. 
WHC-SD-L251-SDS-001

Rev. 1

Page 17

3.2.3.4.5 Each switching panel will include audio links for handset, microphone, select speaker and un-select speaker. The console system will meet the following end-to-end performance specifications (Transmit and Receive).

1) Frequency Response: $300 \mathrm{~Hz}$ to $3300 \mathrm{~Hz},+1,-3 \mathrm{db}$ referenced to $1 \mathrm{Khz}$.

2) Harmonic Distortion: Less than $2 \%$ at rated output.

3) Idle Channel Noise: $65 \mathrm{~dB}$ below rated output. (Audio Mute Enabled)

4) Noise with Tone: $35 \mathrm{~dB}$ below rated output.

5) Line Impedance: $\quad 600$ ohms, $\pm 10 \%$, balanced.

6) Longitudinal Balance: $\quad 70 \mathrm{~dB}$ at $1 \mathrm{kHz}$.

7) Microphone Sensitivity: $-60 \mathrm{dBm}$ to $-22 \mathrm{dBm}$.

8) Automatic Level Control: Output remains constant within $3 \mathrm{~dB}$, over full sensitivity range.

3.2.3.4.6 Plug-in modules will be used to interface up to eight telephone landlines to the switching panel. Modules will accommodate multiple landlines in order to conserve common panel module slots.

3.2.3.4.7 Each land-line interface will be a $600 \mathrm{ohm}$ balanced line and will include on-board DTMF/dial pulse signaling generator. The land-line interface will be an FCC registered device and will support DTMF and dial-pulse signaling and $20 \mathrm{~Hz}, 86 \mathrm{VAC}$ (+/-40VAC) Ring detection.

3.2.3.4.8 The minimum two-wire Return Loss of the interface will be $21 \mathrm{~dB}$ and the minimum four-wire Return Loss will be $40 \mathrm{~dB}$ when terminated with 600 Ohms.

3.2.3.4.9 The recorder Interface will be capable of transmitting conventional channel, or telephone line audio to the logging recorder.

3.2.3.4.10 All signal links destined to external equipment not pertaining to the radio/telephone switching panel, such as base stations and telephone lines, will be brought out to a cross-connect panel for purposes of 
WHC-SD-L251-SDS-001

Rev. 1

Page 18

providing easy system modifications and accessibility with test instruments.

3.2.3.4.11 Each Radio/Telephone switching panel will be equipped with a speaker, hand microphone, headset consisting of ear phones and a lip microphone, and a foot switch.

3.2.3.4.11.1 The speaker will have an impedance of between 8 to 10 ohms and rated for 2 watts nominal power.

3.2.3.4.11.2 The hand microphone will have an impedance of 50 to 200 ohms (dynamic type) or 600 ohms carbon type and be on a jack at the panel.

3.2.3.4.11.3 The headsets will have padded ear phones and both ear phones and lip microphones will be adjustable and be on a jack in the knee hole of the console.

3.2.3.4.11.4 The foot switch will operate in parallel with the radio transmit push button on the panel and will be on a jack in the knee well of the console.

3.2.3.4.11.5 Connecting the headset will disable the panel microphone and speaker.

3.2.3.4.11.6 The panel will be equipped with a red "dispatcher busy" indicator which will light whenever receive push to talk audio is present at the speaker or headsets, or when the push to talk button is activated, or a telephone to intercom call is in progress at the panel.

3.2.3.4.11.7 The selected speaker or headset will be capable of monitoring the receive audio from all channels and groups which are equipped at a console dispatchers position. "Receive audio" from all selected channels will appear at the selected speaker or headset.

3.2.3.4.12 The following is a summary of functional requirements for each of the panel configurations:

3.2.3.4.12.1 Telephone Requirements.

1) Capability to answer: 30 lines.

2) Touch tone dialing pad with DTMF tones. 
3) Provide telephone handsets and headset.

4) Provide patch conference capability with automatic disconnect after either party hangs up within panel equipment.

5) Provide capability to record all calls automatically.

6) Provide visual indication of all calls which are patched, monitored, or conferenced.

7) Provide for $20 \%$ future growth of control positions or circuit capacity.

8) Provide for TDD calls.

9) Provide for the display of ANI and ALI information.

3.2.3.4.12.2 Each panel shall be capable of radio monitoring and controlling 24 conventional radio circuits. The radio control circuits are two-wire and four-wire. Each radio channel to be controlled at a console position will have dedicated radio control module controls. A radio control module will have the following control and indicators:

1) A push-button to select the channel. All select push-buttons at a panel position shall be interlocked such that only one radio may be selected at a time.

2) A LED to indicate that a channel is selected.

3) A LED to indicate that the channel is selected at another console.

4) A LED to indicate incoming audio.

5) A volume control knob for adjusting the receive volume of the speaker or headset.

6) A push-button for muting the channel audio.

7) The capability to select an individual radio channel. Channel selected must be compatible with present control equipment. See Section 6.4 for radio information. 
8) The capability to select F1, F2, F3, F4 or F5 with visual indication of the selected function.

9) Any patched circuits should be able to be manually or automatically disconnected.

10) Patch capability between:

- Radio to telephone line.

- Radio to radio.

11) $2175 \mathrm{hz}$ filters will remove function tones and reduce signaling tone levels from headset/handsets and speakers.

12) Capability to monitor primary receive audio from any of the control circuit receivers. The console will be capable of dynamically muting those control circuits, whose audio is not required.

13) A push-button and indicator will be provided to permit the console operator to select up to six (6) channels for a patch operation. All patched channels will be connected together through the common equipment on a simplex basis such that when one party is transmitting, all other parties are receiving. The console operator, after establishing a patch, will be free to select another channel, or telephone line for communications. Two patches should be available per position.

14) A "transmitter on" indication during Push-To-Talk will be provided.

15) Visual status display of each radio circuit:

- Circuit idle.

- Audio on circuit receive line.

- Circuit selected for use at console position.

16) Parallel Push-To-Talk via:

- Telephone handset/headset.

- Foot switch.

- Instant transmit button per channel. 
3.2.3.4.13 The panel will have the capability to provide DTMF decoder and display of ID information received from mobile units. (See Radio ID Formats, 6.4.1.6).

3.2.3.5 CAD Station Consoles and Chairs

3.2.3.5.1 The CAD work station console will be designed as a sit-down console. The console design will incorporate ergonomic considerations.

3.2.3.5.2 The CAD work station console will be designed so that the dispatcher will be capable of reaching any push-button, switch, or operating device with a minimum of movement. It will be large enough to accommodate an additional computer (HLAN) (see 3.2.5). A wraparound configuration is desirable.

3.2.3.5.3 The console surface height will be 27.5 inches from the floor.

3.2.3.5.4 Extended console writing surface will be provided to accommodate keyboard, mouse and track ball. Please select furniture from the Standard Industrial Commercial Products we have included or provide a choice of your preference.

3.2.3.5.5 The horizontal sight line to the CRT display will be approximately 19 inches.

3.2.3.5.6 All CAD equipment will be installed on slides to assist maintenance personnel in repairing and/or removing faulty equipment.

3.2.3.5.7 No cabinet door will have a swing radius exceeding 28 inches.

3.2.3.5.8 The computer, communication equipment, and ancillary equipment will be installed below the monitor.

3.2.3.5.9 The operator consoles will be designed so that they can be worked on front or back.

3.2.3.5.10 The consoles will be equipped with a rotary dimming switch suitable to control an incandescent task light with the dimming switch wired to a flanged inlet 20 amp, straight-blade plug (NEMA 5-20P) provided within 6 inches of the floor in the console knee well or on the back.

3.2.3.5.11 Provision will be made to allow the dispatch equipment to have access through the console to wiring under the floor. 
WHC-SD-L251-SDS-001

Rev. 1

Page 22

3.2.3.5.11.1 Each dispatch console will have a "DURESS" push-button with an extended guard. It shall be red in color and have a normally open/normally closed contact rated for 300 volts at 10 amps or more. The Buyer will indicate the push-button location on the furnished console drawings.

3.2.3.5.12 The consoles will be metal furniture with the top and front constructed of at least 16-gauge steel or greater. It will be constructed such that a 200-pound person can sit on it with no oil canning of the surface. The sides may be open and if so, the legs will be sturdy enough to carry the full weight of the dispatch equipment plus at least 300 pounds.

3.2.3.5.13 The consoles will have one coat of acrylic primer and two coats of acrylic epoxy semi-gloss finish. The Buyer will select the finish color to be picked from a list of standard colors.

3.2.3.5.14 Console chair.

3.2.3.5.14.1 The console chair will be furnished in accordance with MIL-STD1472D, pages 146-147.

3.2.3.5.14.2 It will be outfitted with arms, height adjustment which is variable from a minimum of 15 inches to 21 inches; seat tilt adjustment, and back tilt adjustment will be provided. The height adjustment and seat tilt adjustment will be via lever action for quick and convenient adjustment to accommodate rapid change of personnel at the consoles. A five caster supported chair will be supplied for stability and safety.

\subsubsection{CAD System Assembly}

3.2.3.6.1 The Seller will assemble one console equipment and software information required for the configuration preparation, viewing, and printing of the dispatch control system data base, CRT displays, and graphic displays in advance of shipment.

3.2.3.6.2 The CRT displays can be configured at any time after the system is delivered.

3.2.3.6.3 The Seller will submit a sketch drawn to scale of the dispatchers station consoles to the Buyer for approval. 
3.2 .4

3.2.4.1

3.2.4.2
Server (Central Processing Unit)

Two servers will be provided. One server functions as a primary server and one functions as a back-up server. Both servers will be identical with all the same features so that either can be identified as the primary server.

Both servers will be on line and have a mirrored data base. In the event one server fails, the other can continue operation with no interruption.

Each server will have a minimum of $\mathbf{4 8}$ megabytes of memory and one gigabyte disk drive.

The primary server will set the date and time for all system components.

Each server will be designed to deliver exceptional performance with a combination of power, speed and versatility. The proposed servers will be suited for intensive compute, file and plot processing, and multi-tasking environments. Each server will support the operating systems, software and hardware interfaces, networking, monitoring input and outputs routing information to disk storage and hard copy output to both high-speed and low-speed printers.

The Seller will provide any air filtering or fans required to operate the server in the specified environment.

Conduit entry for field wiring will be from the bottom. All conduit and wiring penetrations will be protected by the installation of rubber grommets.

Termination panels with barrier-type terminals will be provided.

All shield terminal points will be internally connected to an isolated ground bus which will be connected by the Buyer to the instrumentation ground during installation.

Terminals will be clearly marked with numbers and/or functional design designation as appropriate.

The termination panels will be connected to the $1 / O$ system using 
WHC-SD-L251-SDS-001

Rev. 1

Page 24

Seller provided pre-wired conductor cable with plug-in connectors.

3.2.4.12 Multiplexing of signals to the server may be accomplished in the server or with peripheral equipment at the Seller's option.

\subsubsection{HLAN Computer}

3.2.5.1 The HLAN Computer will consist of a $100 \mathrm{MHZ}$ pentium unit with a 1.2 GB internal hard drive, 16 MB RAM, $256 \mathrm{~KB}$ cache, Quad-speed CD-ROM, 2 MB Graphic accelerator with MPEG 2MB RAM, and ETHERLINK III ISA TP network interface card, integrated sound blaster, headset, microphone and mouse, and P6 overdrive capability. It will be delivered with a standard 101-key keyboard. The monitor will be a 17-inch diagonal flat screen monitor with 256 colors and have a resolution of $1024 \times 768$ pixels.

3.2.5.2 The CPU unit will be installed below the top surface of the console to protect the unit from damage and allow access to the unit for maintenance. Cables will be of sufficient length to allow for access to all cabling for connecting and disconnecting.

3.2.5.3 The keyboard and mouse will be installed on an adjustable swing arm retractable assembly with four degrees of freedom which allows the assembly to be stored under the writing surface when not in use. This assembly will not use any ball-bearing movements. Cabling will be secured to avoid interference to the operator and to prevent damage during either storage or in the operating positions.

3.2.5.4 The HLAN monitor will be installed in the upper right console area to provide visibility to the operator. It will be installed in such a manner as to allow access to the monitor for maintenance and allow access to cabling and power connections.

3.2.5.5 The HLAN printer output will be directed to the laser printer by use of a selector to allow switching of the printer form the CAD system to the HLAN computer. This switching will use automated control.

\subsubsection{Disk Storage}

3.2.6.1 Each server system will include one gigabyte or more disk drive.

3.2.6.2 The redundant drive configuration will provide additional reliability to the system by providing a continuous back-up of all data. Should the 
WHC-SD-L251-SDS-001

Rev. 1

Page 25

primary server fail or be taken off line, processing will be shifted to the second server, which has a mirror disk containing all data stored on the primary disk.

3.2.6.3 The disk subsystem will accommodate a required 90 days of on-line computer-aided dispatch events and location history files, as well as operating system software, applications software, and relational database system software.

Magnetic Tape Subsystem Storage

3.2.7.1 Each server system will have a magnetic tape storage device to provide backup and archiving capability. The tape capacity will be large enough to store all the data on the disk.

3.2.7.2 The magnetic tape subsystem will have sufficient capacity to back up the hard disk drive, and will be the current industry standard.

3.2.7.3 It shall utilize standard removable and re-writable current industry standard tape cartridges.

\subsubsection{Recorder}

3.2.8.1 A CD Recorder will be provided to assist in software updates and provide $C D$ archival data storage. This device will provide the ability to make archival recordings using write once read many media. It will be capable of writing at a $2 X$ rate and reading at a $4 X$ rate. It will be capable of single session or multi-session recording. A single device is required but it will be accessible from either server.

\subsubsection{Printers}

3.2.9.1 High-Speed Event Printer

3.2.9.1.1 The CAD system will have two high-speed event printers for immediate on-line event logging and responding. Sound enclosures will be provided for each printer.

3.2.9.1.2 Each printer will meet the following minimum requirements:

1) 132 characters per line minimum.

2) 300 lines per minute minimum print speed. 
WHC-SD-L251-SDS-001

Rev. 1

Page 26

3.2.9.1.3 Each printer will provide a buffer such that no alarm information is lost due to slow printing speed.

3.2.9.1.4 Each printer will utilize tractor/pin feed fan-fold paper.

3.2.9.1.5 It will be possible to annotate and read the print copy while the paper is still in the machine.

3.2.9.1.6 The print head or mechanism will not obscure the most recently printed line of characters. The printer may require a line feed button on the printer or an action on the dispatch consoles to send enough line feeds to the printer to enable the most recent line of text to be visible.

3.2.9.1.7 Each printer will be supplied with a stand designed for holding the printers.

3.2.9.1.8 Each printer will be supplied with a basket to hold printed paper output.

3.2.9.1.9 Each printer will be supplied with the capacity to hold a box of paper in-feed.

3.2.9.1.10 Thermal printers are not acceptable.

3.2.9.2 Laser Printer

3.2.9.2.1 The CAD system will have two laser printers for logged historical data, system reconfiguration, and any other applicable applications.

3.2.9.2.2 The laser printer will be capable of interfacing with the CAD system as well as the HLAN system computer. It will be a Laser Jet 3 or 4 .

3.2.9.2.3 The laser printers will meet the following minimum requirements:

1) Eight pages per minutes $(81 / 2 \times 11$ page size)

2) Three hundred dots per inch

3) Two Mb RAM, expandable to $5 \mathrm{Mb}$

4) Parallel and serial interfaces

5) 13 resident scalable fonts

6) 150 sheet paper tray

7) Automatic or single sheet feed 


\subsubsection{Audio Tape Recorder}

3.2.10.1 Two audio tape automatic recording systems will be provided.

3.2.10.2 The audio tape recording system will record digitally and on receipt of incoming information will automatically record the time and date. The recording will include the ANI information from the telephone system.

3.2.10.3 The audio tape recorders will be capable of being accessed from any of the four dispatch stations.

3.2.10.4 Each audio recording system will consist of two digital audio tape drives and an instant playback module.

3.2.10.5 The instant playback module will have a capacity of 30 minutes.

2.3.10.6 Each digital audio tape drive will have a capacity of 600 hours or more.

3.2.10.7 The audio recording system will be capable of recording 32 channels simultaneously.

3.2.10.8 There will be keys to provide for a ready, record, play, stop, and eject.

Also, there will be function keys for playback, fast forward, and rewind.

3.2.10.9 An LED display will be provided and will consist of a minimum of four lines with 40 characters per line. The display information will be utilized to access recorded information. The recorded information will be capable of being accessed by any of the four dispatch stations.

3.2.10.10 An end of tape and system failure alarm will be provided. The alarm will consist of both audio and visual. The visual signal will be transmitted to the four dispatch stations.

3.2.10.11 The digital audio recorder will have a channel monitor, channel mixing, simultaneous report and playback, fast forward and rewind in three speeds.

3.2.10.12 The search time for the instant playback module will be in less than 5 milliseconds. 
WHC-SD-L251-SDS-001

Rev. 1

Page 28

3.2.10.13 The average search time on the digital audio tape drive will be 30 to 45 seconds. The search criteria will be time/date, channel, next/previous, and contents.

3.2.10.14 The input characteristics per channel will have a frequency response of a usable band of 300 to 3,300 Hertz and idle channel noise will be less than $35 \mathrm{~dB}$. System will be capable of interfacing to ISDN interface.

3.2.10.15 Channel isolation shall be a minimum of $55 \mathrm{~dB}$.

3.2.10.16 The unit will have adjustable audio gain control.

3.2.10.17 Recording will be initiated on voltage sensing.

3.2.10.18 Each channel will be capable of generating a warning tone to the source being recorded.

3.2.11 General Information

3.2.11.1 All hardware components will be selected with ergonomic considerations.

3.2.11.2 The plane of each CRT face will be capable of being tilted to compensate for various dispatch operator's height.

3.2.11.3 Each CAD station will provide an audible annunciator for alarms.

3.2.11.3.1 The auditory alert subsystem provided by the CAD station will not be similar to any Hanford plant emergency system, i.e., criticality alarm $(\mathrm{AH}-\mathrm{OH}-\mathrm{GAH})$, wailing siren, wavering siren, steady siren, ringing bell, or clanging bell.

3.2.11.3.2 The intensity of the auditory alert will be adjustable with a maximum capability to achieve 80 decibel sound level at a distance of three feet. This adjustment will be adjustable by maintenance personnel only and not accessible to the operators.

3.2.11.3.3 The frequency of the auditory alert will be between $500 \mathrm{~Hz}$ and 3,000 $\mathrm{Hz}$. However, a frequency of $1,000 \mathrm{~Hz}$ is preferred.

3.2.11.4 The CAD work station will contain all processors, communication devices, and memory required to meet the functional requirements of this document and be optimized for performance using Standard Industrial Commercial Products. 
WHC-SD-L251-SDS-001

Rev. 1

Page 29

3.2.11.5 The console cabinets will provide for cabling and communication via cable access for all equipment provided on top of the console of the cabinets.

3.2.12 Hardware Maintainability

3.2.12.1 Modularity

3.2.12.1.1 The local dispatch station, servers, signaling equipment, communication equipment, and peripheral equipment will be modular in construction.

\subsubsection{Power-On Replacement}

3.2.12.2.1 Equipment at the dispatch station, communication equipment, monitors, computers, etc., will be capable of being changed with the system power on with no damage to the system components.

\subsubsection{Redundancy}

3.2.13.1 System redundancy requirements are imposed in order to minimize the loss of one of the dispatch stations, servers, storage devices, and recording equipment.

3.2.13.2 All redundant components will be in hot-standby and their status (normal/failed) will be continually monitored and will share a mirrored data base.

3.2.13.3 Whenever a redundant component is required by failure of the primary component, switching from the primary to the secondary component will be automatic and occur within one second of a failure and be audibly annunciated.

3.2.13.4 All automatic switching will be logged on the log printer and appropriately displayed.

3.2.13.5 No single failure will cause the loss of more than one of the two fixed mass storage devices or the loss of more than one mass storage device with removable storage media.

3.2.13.6 The system design objective was for maximum availability. Standard Industrial Commercial Practices and Products minimize loss due to single failures. Loss of power is an example of a single failure that can be designed around but not ruled out.

3.2.13.7 Each station will be capable of providing complete back-up for the other station. 
WHC-SD-L251-SDS-001

Rev. 1

Page 30

3.2.13.8 The back-up mode will be implemented by either automatically or manually loading a different configuration.

\subsection{SYSTEM SOFTWARE}

4.1 General Requirements

4.1.1 The proposed CAD application software will be capable of supporting alarm and call intake, dispatch, unit status and management reporting and, at a minimum, provide the functions and features listed below.

4.1.2 It will be the Seller's responsibility to verify that the software is virus free by a software virus scan. The software virus scan program will be acceptable to the Buyer and the virus scan will be performed in the presence of the Buyer.

\subsection{Basic Features of CAD}

4.2.1 The CAD software will support dedicated, as well as combined calltaker and alarm monitoring plus dispatcher arrangements.

The CAD software will support a single agency performing multiple functions, i.e., all fire, patrol and EMS activities. A single call or alarm entry must be routed to all dispatch positions simultaneously, or to any one station, or any combination of stations at the configuration of the system supervisor.

4.2.3 The CAD software will produce an audit trail, logged to the server. This log will occur immediately after the creation of a call for service or alarm, call dispatch, and after every status change.

4.2.4 All CAD terminals will have multiple windows available. At least two windows will be available upon command. At least two partial screens will be able to be displayed at one time.

4.2.5 The software design will make extensive use of table driven parameters allowing easy modification by the system supervisor without the requirement for programmer support. These modifications will be able to be made while the system is active.

4.2.6 A library of utility programs will be supplied to maintain the data files. These programs will be accessed through menus and be user friendly.

The operator will be able to route the contents of the screen to any printer or console on the network. 
Rev. 1

Page 31

4.2 .8

4.2.9

4.2.10

4.2.11

4.2.12

4.3

\subsection{1}

4.3.1.1

4.3.1.1.1

4.3.1.1.2

$4 \cdot 3 \cdot 1 \cdot 1.3$

4.3.1.2.1

Backup of the files will be able to be accomplished without taking either system out of service or having any impact upon the response time or performance.

The systems will make use of programmable function keys for all frequent operations, to reduce the number of required keystrokes.

Menus will be provided to select the various functions that are available in the CAD programs. Access authorization will control the functions that are available to each user. Only those functions which are allowed by access control will be displayed on the screen.

The CAD systems will have an on-line, context-sensitive help facility. The dispatcher will be able to pick the correct selection from any list displayed by a single command from a function key or a track ball by pointing to that selection.

The CAD system will have a "scratch pad" feature where information can be entered by category. The information contained in this file may be searched and displayed using the category name.

Specific System Requirements

System Security

The software will provide a security system that contains a profile for each dispatcher/user. This profile will control:

Which global functions the dispatcher/user can access.

Which basic functions, call taking, dispatching, systems administration, etc., the dispatcher/user is authorized to perform.

Which commands or function keys the dispatcher/user has the right to use.

\section{Passwords}

The password files/records will be protected against unauthorized access and viewing.

Dispatcher/user passwords will be of variable length, with a minimum length of six (6) characters.

Each dispatcher/user's password will be valid for a period as definable by system parameters. 
WHC-SD-L251-SDS-001

Rev. 1

Page 32

4.3.1.2.4 The system will support password aging without modifications to the operating system.

4.3.1.2.5 Reserved.

4.3.1.2.6 Reserved.

4.3.1.2.7 Reserved.

4.3.1.3 Dispatcher/user access to all system files will be restricted based on access rights granted by the system, via the dispatcher/user profile, and the dispatcher/user ID.

4.3.1.3.1 File access rights will include, but not be limited to, read only, $\mathrm{read} / \mathrm{write}$, delete, and execute.

4.3.1.3.2 All invalid file accesses will be logged; the log information will contain the date and time of the attempt, type of access requested, the ID of the dispatcher/user requesting the access, and the reason for failure, all without modifications to the operating system.

4.3.1.3.3 The information in the log will be available for displaying and/or printing by a user with the proper security level without modifications to the operating system.

4.3.1.3.4 The information in the log will be able to be purged by a user with the proper security level without modifications to the operating system.

4.3.1.4 The software, under security level control, will provide a facility to display CAD activity. This will be used to allow shift supervisors and any other authorized dispatcher/user to monitor the dispatch activity, without affecting the actual operation of the CAD.

\subsubsection{Log On/Log Off Control}

4.3.2.1 All consoles will be locked from all activity except log-on when a dispatcher/user is not logged onto it.

4.3.2.2 The system will provide a log-on of all unsuccessful attempts to log onto the CAD system.

4.3.2.2.1 The log will contain the date and time for the log-on attempt, the terminal/work station ID used, the attempting dispatcher/user identification and the reason for the failure.

4.3.2.2.2 The information in the log will be available for displaying and/or printing by a user with the proper security level. 
WHC-SD-L251-SDS-001

Rev. 1

Page 33

4.3.2.2.3 The information in the log will be able to be purged by a user with the proper security level.

4.3.2.3 Each work station dispatcher/user will log on before being recognized by the system. The log-on identification of the dispatcher/user will be validated, using a passwod, by the system before that dispatcher/user can perform system functions. The log-on identificaiton will become part of the CAD call record for all calls created or dispatched by a dispatcher and for all alarm activity responded to, and sensor mode changes made, by a dispatcher.

4.3.2.4 The CAD will have the ability to quickly log a dispatcher/user off and log a new dispatcher/user on without having to exit from the CAD or re-start the program.

4.3.2.5 A message will be displayed to the user when they sign on indicating that their password has expired. The dispatcher/user will be required to change their password prior to accessing the system functions.

4.3.3 CAD System Response Time

4.3.3.1 Dispatching vehicles to calls for service received is often a time critical event. Because of this, the computer system cannot add appreciably to delays in responding to a call.

4.3.3.2 Because of the above, the proposed CAD system will be designed to meet the following general performance criteria:

4.3.3.2.1 The system will have the capability of transferring an incident from the call taker to the dispatcher (in most cases this will be the same person) within a maximum of two seconds.

4.3.3.2.2 The system will also have the capability of transferring partial incident information to the dispatcher after only the incident type and location have been entered. The call taker will continue to take additional information and enter it into the incident entry screen. Once they complete the incident, they will transfer the remainder of the incident information to the dispatcher. All information associated with the incident, including the "quick transfer" will be recorded in the audit trail.

4.3.3.2.3 The system will optimize the use of hardware and software resources to obtain the highest possible throughput. Within the database area, specialized indexes will be maintained to reduce $\mathrm{I} / \mathrm{O}$ access to disk. 
4.4 Call Taker Functionality

4.4.1 Call Creation

4.4.1.1 Upon receipt of a call for service, the software will allow for the capture and maintenance of the following call information:

4.4.1.1.1 Incident type (table-defined). The CAD software will provide an online help function for valid incident types. If the operator enters an incorrect, or a partial incident type the system will display a list of valid incident types. The user will be able to select the correct incident type from that list. The selected incident type must then be filled in by the system in the call for service screen.

4.4.1.1.2 Incident location (geo-processed) in CAD.

4.4.1.1.3 Incident priority (table-defined based on entered incident type). The software will allow the call-taker to override the table-defined priority value and enter a different priority level.

4.4.1.1.4 Indication if the event is in progress. The default will be set by the incident type, but modifiable by the call-taker.

4.4.1.1.5 Complainant's name.

4.4.1.1.6 Complainant's address.

4.4.1.1.7 Complainant's telephone number.

4.4.1.1.8 Call narrative/comments.

4.4.1.2 The software will allow the call taker to capture the caller's information in any order. A facility will be provided to input call for service information in either a command line entry, or by the use of numbered field or lines. The call taker will be able to move around the input screen using any combination of field or line numbers, tabbing and/or by a next line key and/or track ball.

\subsubsection{ALI and ANI Information}

4.4.2.1 The software will be capable of interfacing with the existing 5ESS telephone switching system and the associated C-3 telephone database.

4.4.2.1.1 The 5ESS is capable of providing calling line identification directory number (CLID) on all lines originating in the Hanford system lcurrent version is Revision 5E7). 
4.4.2.1.2 The C-3 database holds real time information concerning the site location of all directory numbers in the Hanford system. This database is an oracle based database running on a UNIX platform, Version 2.3, (C-3 Version is currently revision 4.9 ).

4.4.2.1.3 The C-3 database will file transfer an ASCIl file composed of directory number, area, building and room via existing HLAN connection.

4.4.2.1.4 Hanford PeopleCore Database will file transfer an ASCIl file containing additional information related to directory number via an existing HLAN connection.

4.4.2.3 If the location is not correct, the terminal user will be able to input the correct location. The location of the 911 call will be retained in the incident history.

\subsubsection{Location Validation}

4.4.3.1 Upon entry of the incident location, the application software will provide a look-up to the geographic database. This process will facilitate qualifying the given incident location and its' block range (if applicable) as a valid address and identify the appropriate patrol, fire, or EMS as defined. The geographic area information will be capable of being read from an off-line graphic system. Currently this information is available on AutoCAD Release 12, Washington State Plane, South Zone, NAD83, metric.

4.4.3.2 The system will utilize a look-up for street names, intersections and common place names.

4.4.3.3 If the system is unable to provide an exact location match, a list of potential matches, will be displayed to the call-taker.

4.4.3.4 The call-taker will be able to select the correct location from the displayed list, scroll forward for other potential locations, or restart the location look-up with a new location. If the user selects from the displayed list the software will automatically place the correct location in the incident location field.

\subsubsection{Advisory Information}

4.4.4.1 The software will also perform necessary look-ups to determine if any of the following conditions exist at the entered incident location:

4.4.4.1.1 Location information. This information will be used for displaying hazards, or special instructions relating to a location. Notes will be 
able to be associated with various geographic locations; grids, street segments, intersections, or specific addresses.

4.4.4.1.2 Prior calls for service history at the incident location.

4.4.4.1.3 Duplicate event detection. The software will detect and notify the call-taker of the potential of a duplicate incident on active calls. The detection will take into consideration location and time. The time parameters used by the software for this detection will be user definable.

4.4.4.1.4 Standard Operating Procedures (SOPs). CAD will maintain a file of SOPs. Each CAD call type can have multiple related SOPs. These SOPs can be used to advise dispatch or patrol personnel on how that specific call type is to be handled. The detailed information on the SOP will be displayed in a separate area or window on the screen, allowing the call to be displayed at the same time as the SOP.

4.4.4.2 CAD will flag the user of the existence of advisory information and display this information upon demand. This information will be displayed without losing the call information from the screen. If a flag was displayed to the user, a record of that fact will be made part of the call record.

4.4.4.3 At any time during the life of an active call, the users will be able to quickly display the advisory information for that particular call.

\subsubsection{Urgent call "quick dispatch"}

4.4.5.1 The software will allow the call-taker to pass an urgent, but incomplete call for service (containing only basic call type and incident location information), on for immediate dispatch, while the remainder of the call intake information is being solicited. When the call-taker has completed the call, the up-dated information will be sent to the dispatcher who is handling the call.

\subsubsection{Interruption of call intake for more urgent call}

4.4.6.1 The software will provide the ability to save multiple partially completed calls for service. A summary of all partially completed calls will be displayed on the user's terminal. The call-taker will be able to retrieve these partially completed calls.

\subsubsection{Alarm Calls}

4.4.7.1 The AP supervisor software will allow for the creation of calls for service using alarm numbers. The AP will have an alarm file that 
WHC-SD-L251-SDS-001

Rev. 1

Page 37

contains the location and description of the alarm. This information will be communicated to the terminal user when the alarm is input. The CAD system will automatically create an incident from a valid alarm.

\subsubsection{Call Routing}

4.4.8.1 Since the call-taker may also be the dispatcher, they will be able to dispatch multiple units directly from the call screen. CAD will automatically route a new call to the appropriate dispatcher based on the established parameters.

\subsubsection{Pending Call Queue}

4.4.9.1 The software will provide an interactive, dynamic call queue for maintaining calls for service awaiting dispatch. Calls awaiting dispatch in the call queue will be stacked (sorted) first by priority and then within each priority by elapsed time since the call was received.

\subsubsection{Pending Call Display}

4.4.10.1 The software will provide for a display of pending calls on the same terminal that is used for dispatching (interactive terminal). This will be in a split screen or separate window.

4.4.10.2 The dispatcher will be able to scroll the pending incident display if there are more pending incidents than can be displayed at one time.

\subsubsection{Pending Call Timers}

4.4.11.1 The software will provide for timers, based on incident type, and whether in progress or not, for pending dispatches. The software will highlight the display of any pending incident that has exceeded the timer. A function will be provided to reset the timer, without having to recall the pending incident to the screen.

\subsection{Dispatch Functions}

\subsubsection{Selecting Pending Incidents}

4.5.1.1 The dispatcher will be able to:

4.5.1.1.1 Select the highest priority alarm incident from the pending incident display with a single key stroke at the AP supervisor,

4.5.1.1.2 Select calls from the pending queue in any order. 
Rev. 1

Page 38

4.5.1.1.3 Place a call back in the pending queue after reviewing it.

\subsubsection{Dispatch Screen}

4.5.2.1 The CAD software will provide the following basic functions and/or information when a call for service is retrieved for dispatch:

4.5.2.1.1 All call for service information obtained during call intake.

4.5.2.1.2 Location advisory information. This information will be used for displaying hazards, or special instructions relating to a location. These notes will be maintained by an on-line program. Notes will be able to be associated with various geographic locations; grids, street segments, intersections, or specific addresses.

4.5.2.1.3 Prior calls for service history.

4.5.2.1.4 Duplicate event detection. The software will detect and notify the calltaker of the potential of a duplicate incident on active calls. The detection will take into consideraiton location and time. The time parameters used by the software for this deteciton will be user definable.

4.5.2.1.5 Standard Operating Procedures (SOPs). CAD will maintain a file of SOPs. Each CAD call type may be able to have multiple related SOPs. These SOPs may be used to advise dispatch or patrol personnel on how that specific call type is to be handled. The detail information on the SOPs will be displayed in a separate area or window on the screen, allowing the call to be displayed at the same time as the SOPs.

\subsubsection{Unit Recommendation}

4.5.3.1 CAD will automatically provide the dispatcher with a unit recommendation. This recommendation will be composed of a specific unit identifier and will be derived taking into account the following basic elements:

4.5.3.1.1 Incident type to determine the type and number of units to recommend.

4.5.3.1.2 Real-time unit status to determine unit availability. All unit recommendations will correspond to the current, real-time status of all resources. The software will never recommend a unit that is on another assignment or otherwise unavailable for dispatch. The software will facilitate the definition and recommendation of second, 
WHC-SD-L251-SDS-001

Rev. 1

Page 39

third, etc., level units in the event a primary response unit is in an unavailable status.

4.5.3.1.3 Patrol and unit recommendation will be based on beat plans.

4.5.3.1.4 Future fire unit recommendation and EMS will be based on a user maintainable run card system.

4.5.3.1.5 Future fire unit recommendation will accommodate multiple alarm levels.

4.5.3.1.6 The CAD system will have the capability to provide in the future for temporary change of quarters of fire units. The dispatch recommendation will be based on the move to cover locations.

4.5.3.1.7 The unit recommendation of future fire and EMS units will show the station number and pager tone codes associated with each fire or EMS unit.

4.5.4 Dispatching:

4.5.4.1 The dispatcher will have the capability to accept the system-provided unit recommendations with a single keystroke, or override these and provide one of his/her own.

4.5.4.2 The dispatcher will have the capability to select a unit that is on a lower priority call. A single keystroke will remove the unit from the previous call (preempt) and assign it to the call to be dispatched. If the unit is the last one on a call, the call will be automatically placed in the pending call queue and held for that specific unit.

4.5.4.3 When that unit clears the higher priority call, the call they were preempted from will automatically be recommended for dispatch. Call times associated with assignment and re-assignment will be kept in the call history file.

4.5.4.4 The dispatcher will have the ability to change the primary unit at the time of dispatch or at any time during the handling of the call. The primary unit is the unit who is responsible for completing any reports.

4.5.4.5 CAD will provide the ability to stack or assign low priority calls to a busy unit. These calls will be time stamped, and displayed in the pending call display, with an indication that call has been stacked to a unit. When the unit clears from one call, the software will provide an indication that the unit is now available for the stacked, or preempted call. CAD will time stamp when the unit is en route to the new call. 
WHC-SD-L251-SDS-001

Rev. 1

Page 40

4.5.4.6 Upon acceptance of a unit dispatch recommendation, or input of a dispatcher's own unit recommendation, the software will automatically and dynamically update the status of all affected units throughout the CAD system. All CAD terminals will be automatically updated with the new status information without operator intervention.

4.5.5 Call and Unit Status Maintenance

4.5.5.1 The software will dynamically and interactively track the status of all resources which are defined within the computer-aided dispatch system.

4.5.5.2 The software will track the following minimum call and unit status conditions, for each unit assigned to a call:

4.5.5.2.1 Call Received

4.5.5.2.2 Dispatched

4.5.5.2.3 En Route

4.5.5.2.4 Arrived on Scene

4.5.5.2.5 Transporting

4.5.5.2.6 Arrived Transport Destination

4.5.5.2.7 Clear Unit and/or Call

4.5.5.3 Recorded times (e.g., dispatched, arrived, etc.) will be maintained in military (24-hour clock) format. The software will capture both minutes and seconds. All unit status changes will be automatically time stamped and become part of the call for service history.

4.5.5.4 The clock time used by all applications will be able to be reset while they are operational, and without having to log users off, or re-boot the system. If the systems are interfaced to an optional clock synchronizaiton system, the synchronizaiton system will perform the clock resetting functions.

\subsubsection{Updating Unit Status}

4.5.6.1 Dispatchers will be capable of updating unit status through keyboard input of appropriate unit identifiers and a single function key.

4.5.6.2 The software will allow dispatchers to update a unit status while performing any call taking or dispatching function within the CAD system by providing easy accessibility to an interactive command line at all times. This command line will allow multiple units to have the same status update at the same time. 
WHC-SD-L251-SDS-001

Rev. 1

Page 41

4.5.6.3 Updating unit status will be able to be accomplished without losing the call information that is displayed on the screen. If the cursor is repositioned to perform the command, it will be automatically returned to the correct screen and cursor position where the dispatcher left off without losing any information.

4.5.6.4 The software will allow an alternative method of inputting status changes that would accept a function key command first and then the unit number(s) or visa versa.

4.5.6.5 The software will provide dispatchers with the capability to clear all units with a single command or clear all units with the exception of specified ones.

4.5.7 Updating Calls

4.5.7.1 The software will allow either call-takers or dispatchers to review an active call and update the call with corrections or additions.

4.5.7.2 The software will allow assisting units to be added to a call after it has been dispatched.

4.5.7.3 The dispatcher must be able to escalate the fire alarm level. CAD will make additional unit recommendations based on the new alarm level and run card recommendations.

4.5.7.4 Releasing and Reassigning Units

4.5.7.5 The software will allow units to be reassigned from one call to another. The previous call will be returned to the pending queue if the reassigned unit is the last unit on the call.

\subsubsection{Call Completion}

4.5.8.1 CAD will allow either single units or all units on a call to be cleared with a command or function key. When the last unit on a call is cleared, CAD will require a disposition code and an indicator when a report is required before clearing the call.

4.5.8.2 The software will provide for the capture of a user-maintainable call disposition code, an indicator that a report is or is not required, and call completion comments.

\subsubsection{Report Numbering}

4.5.9.1 The software will assign unique sequential case numbers, following numbering standards for those incidents in which a written report is to 
WHC-SD-L251-SDS-001

Rev. 1

Page 42

be taken. The software will provide the option of either having the report number automatically generated, or generating the number upon demand.

4.5.9.2 The software will allow for the resetting of the sequential numbers at any time to a desired number.

4.5.9.3 The software will allow the reassignment of an existing related case number, instead of the system generated number.

4.6.

Status Monitoring

4.6.1

Pending Calls

4.6.1.1 The software will display the waiting call queue in a window of the screen. The dispatcher will be able to quickly select the desired call to dispatch.

4.6.1.2 The waiting call queue display will present all waiting calls for service in priority order, and within each priority elapsed time since call receipt. Displayed information will include a minimum:
4.6.1.2.1
Call Priority
4.6.1.2.2
4.6.1.2.3
Incident Type
Location
4.6.1.2.4 Time of Call Receipt

4.6 .2

Active Call Status

4.6.2.1

The dispatcher will be able to display a summary of all active calls by depressing a function key.

4.6.2.2 The active call status display will include at a minimum:

4.6.2.2.1 Time Call Received

4.6.2.2.2 Call Number

4.6.2.2.3 Priority

4.6.2.2.4 Call Type

4.6.2.2.5 Call Type Description

4.6.2.2.6 Location

4.6.2.2.7 Units Assigned

4.6.2.2.8 Status Times Associated With Each Unit

4.6.2.2.9 Name of Person(s) Dispatched

4.6.2.3

The dispatcher will be able to quickly select any call from the display for updating. The dispatcher will be able to scroll the active call display, if there are more calls than can be displayed at one time. 
WHC-SD-L251-SDS-001

Rev. 1

Page 43

4.6.3 Changing Duty/Roster/Shift Changes

4.6.3.1 CAD will provide the ability to quickly change the assignment of a single unit including, on or off duty, area of coverage, officer(s) assigned and whether recommended for dispatch.

4.6.3.2 CAD will also provide the ability to pre-build a shift and allow a dispatcher with the required access control the ability to review the roster and make any necessary changes.

4.6.3.3 After the roster has been reviewed and updated, CAD will provide a command to activate and deactivate shifts. Each shift will be userdefinable and allow for over-lapping shifts.

4.6.4 Calls for Service History

4.6.4.1 Once an incident is closed out (all units cleared) and an incident disposition is captured, the software will maintain the call detail as calls for service history. The call for service history will include all information which was generated as part of the call intake, dispatch, and unit status tracking process specific to each incident.

4.6.4.2 The calls for service history file will allow for the on-line display of closed calls. Access control will control which users have the ability to access closed calls and which users have the ability to update or change closed calls.

4.6.5 Unit History

4.6.5.1 The CAD system will capture non-call related unit history in a unit history file.

4.6.5.2 The unit history file will allow for the on-line inquiry and display of unit activity.

4.7 Management Reports

4.7.1 Pre-Formatted Reports

4.7.1.1 Users will be able to generate management reports by selecting the desired type of report from a CAD menu and entering the desired selection criteria and date/time ranges. The system will be able to create, delete, and modify pre-formatted reports as needed and place these reports into the CAD menu system. The reports to be provided include: 
4.7.1.1.1

4.7.1.1.2

4.7.1.1.3

4.7.1.1.4

4.7.1.1.5

4.7.1.1.6

4.7.1.1.7

4.7.1.1.8

4.7.1.1.9

4.7.1.1.10

4.7.1.1.11

4.7.1.1.12

4.7.2

4.7.2.1

4.7.3

4.7.3.1

5.0

5.1

5.1.1

5.1.2

5.1.3

5.1 .4

5.1 .5

5.1 .6

5.1 .7
Call taker/dispatcher activity for a selected time period.

Response time summary.

Calls for selected unit for a given time period.

Response time analysis by unit.

Response time analysis by type of call.

Number of calls received by type and time of day, day of week.

Officer activity summary.

Summary by disposition code.

Activity by type and shift.

Hour of day statistics.

Day of week statistics.

Event priority overrides.

Ad-Hoc Reports

A capability of generating ad-hoc reports using any data field within CAD will be made available. The generation of reports must take place as a secondary/background function of $C A D$ so $C A D$ response time is not affected.

Mapping Capabilities

Seller will describe how their system incorporates computerized mapping into CAD. Seller will include a detailed explanation regarding how their system's maps are updated.

\section{SYSTEM FUNCTIONS}

Display

All displays will be organized in a logical hierarchical manner.

Each display will be uniquely labeled and identified and will include display of current date and time with resolution to two seconds.

Overview group alarm summary and status will be performed at the AP supervisor

Graphic displays will be Seller-formatted,configurable by the user.

The representation of alarm status by color coding and flashing will be consistent on all displays that provide alarm status on the AP Supervisor.

Display software will provide up to 16 colors.

Numerical values, such as alarm points, will be Buyer configurable. 
WHC-SD-L251-SDS-001

Rev. 1

Page 45

5.1.8 Letter values will be Buyer configurable.

5.1.9 All displays will be automatically updated when they contain status information.

5.1.10 The display at the AP supervisor will provide feedback and response to control actions.

Group Display through the AP Supervisor

Groups will be uniquely identified by name and number.

Alarm status will be identified by color coding and flashing symbols.

5.2.3 Discrete status will be clearly indicated.

5.2.4 Group displays will provide graphical and textual representation of device, status, and alarms.

$5.2 \quad$ Group Display

5.3 Alarm Summary Display

5.3.1 Alarm summary displays will provide a prioritized listing to read all current alarms.

5.3.2 Information display will include the time of the alarm, occurrence, tag name, alarm type, and alarm description.

5.3.3 Alarm status activated and acknowledged will be indicated by a combination of color coding, and flashing.

5.3.4 Flashing will be utilized for un-acknowledged alarms.

5.3.5 Acknowledged alarms will be steady.

5.3.6 Alarms which have been cleared will be removed and the display alarm list will be restacked to eliminate blank lines.

5.4 Alarm Annunciation

5.4.1 Activation of an alarm will be annunciated visually and audibly such that attention is commanded without preempting current activities. 
WHC-SD-L251-SDS-001

Rev. 1

Page 46

5.4.2 Sufficient information will be provided to enable rapid progression to display that will permit alarm acknowledgement by utilizing two key strokes or less.

5.4.3 If the alarm is configured on the current display of the CRT, the display will be dynamically updated.

5.4.4 Alarm indication and all displays will be color coded according to the level of importance.

5.4.5 The capability will be provided to allow the Buyer to assign a minimum of four colors to each alarm.

5.4.6 Control of the displayed alarms will be provided to prevent them from becoming a nuisance as in the case of simultaneous or chattering alarms.

5.4.7 Alarm activation will be automatically logged to the log printer and log file/database in the order of occurrence.

5.4.8 Refer to Section 1.2.4 for log alarm information.

5.4.9 Alarm will appear on the alarm summary display in the order of priority.

5.5

Alarm Acknowledgement and Clearing

5.5.1 Dispatcher alarm acknowledgement will be provided.

5.5.2 For an alarm to be acknowledged it must be acknowledged from any display showing the alarm.

5.5.3 Acknowledgement of an alarm will cause the alarm indicator to be set from flashing to steady and cause the audible annunciator to be silenced.

5.5 .4

Alarm acknowledgement will be logged in the log printer and to the log file/data base.

5.5.5 Logged information will be logically linked to the alarm annunciation information and will include date and time of acknowledgement, tag name, and alarm type.

5.5 .6

The alarm will remain active on all appropriate displays until it has cleared.

5.5.7 Alarm inhibit functions will be provided. 
WHC-SD-L251-SDS-001

Rev. 1

Page 47

5.5.8 Alarm inhibit is intended to suppress chronic alarms in the event of equipment failures.

5.5.9 Clearing of an alarm will be logged on the log printer and to the log file/data base.

5.5.10 Logged information will be logically linked to the alarm annunciation and acknowledgement information, and will include date and time of clearing, tag name, reason for alarm activation, and alarm type.

5.5.11 Fire Alarm Bypass as supplied in the AP supervisor

5.5.11.1 Provision will be provided to quickly bypass alarms by:

5.5.11.1.1 Individual fire zones.

5.5.11.1.2 Trouble alarms only.

5.5.11.1.3 All fire and trouble alarms (with one user entry).

5.5.11.1.4 Front button alarms.

5.6 CAD System

5.6.1 The CAD system will not require a knowledge of computer programming or special training other than the Seller's standard training classes.

5.6.2 Changes to the operating configuration of the CAD station will be possible without interrupting monitoring and control funcitons.

5.6.3 Adding or removing a dispatch station will not bring down the POC.

5.7 Display Definition at the AP supervisor

5.7.1 An interactive display definition capability will be provided to configure, construct, and perform a pre-formatted overview group alarm and summary displays.

5.7.2 The display definition capability will provide the following functions:

5.7.2.1 A menu-driven fill in the blanks approach to display generation.

5.7.2.2 Fully support all features of pre-formatted displays. 
WHC-SD-L251-SDS-001

Rev. 1

Page 48

5.7.2.3 Reference process variables by tag name during display definition and construction.

5.7.2.4 Add new displays and modify existing displays.

5.7.2.5 Delete displays and automatically recover disk storage.

5.8 Graphics Editor

5.8.1 An interactive graphics editor will be provided that supports the definition and construction of the Buyer formatted graphics displays.

5.8.2 The graphic editor will provide the following functions:

5.8.2.1 Fully support all features of the Buyer-formatted displays.

5.8.2.2 Add new displays.

5.8.2.3 Modify the content of existing displays.

5.8.2.4 Delete existing displays and automatically recover disk storage.

5.8.2.5 Build new displays from existing displays.

5.8.2.6 Pre-define standard process symbols.

5.8.2.7 Ability to create Buyer-defined symbols.

5.8.2.8 Color selection for all symbols and tags.

5.8.2.9 Random selected delete, copy, or move picture elements.

5.9 Configuration Documentation

5.9.1 The Seller will describe specifically how these requirements are met.

5.9.1.1 A description of any special hardware or software will be provided.

5.9.1.2 The software will provide a method to document the CAD monitoring and control configuration.

5.10 Archiving

5.10.1 The archive system will be capable of selectively archiving to the laser printer the following events and information.

5.10.1.1 Modifications of the alarm points. 
5.10.1.2 Establishment of alarm inhibits.

5.10.1.3 Alarm information.

5.10.2 The archive system will also indicate selective archiving to the removable off-line storage media.

5.10.3 All archive information will include date and time of occurrence.

5.11 Ap supervisor Display Selection

5.11.1 All displays will be accessible in a logical, hierarchial manner that permits rapid progression vertically between levels and laterally within levels.

5.11.2 All displays will be directly accessible.

5.11.3 Overview displays will support the selection of group displays.

5.11.4 Group displays will support the following control functions; alarm acknowledgement, modification of output signals, change of output state on or off.

5.11.5 Graphic displays will support the following control functions: Alarm acknowledgement, change of output status on and off.

5.12

Alarming at the AP supervisor

5.12.1 Alarms will be generated on sensor, telephone, and radio inputs.

$5.13 \quad$ Communications

5.13.1 Communication capability will be provided that links all CAD stations together on a common communication network.

5.13.2 The networks will support peer-to-peer communication between all CAD stations.

5.13.3 The AP supervisor will provide and have access to alarm information generated by other nodes unless that data is excluded under configuration control.

5.13.4 The communication protocol will support error checking and retransmission upon error detection. 
WHC-SD-L251-SDS-001

Rev. 1

Page 50

5.13.5 The network will automatically route around single communication link failures between any two nodes on the network.

5.13.6 The communication network will be periodically monitored by an online diagnostic for faults.

5.13.7 Communication faults will be displayed.

5.14 Diagnostics

5.14.1 The CAD station will perform automatic self-diagnostics after power up or restart conditions.

5.14.2 Using the standard self diagnostics of Standard Industrial Commercial Products, tests will perform these functions at the server, microprocessor and network level and display results.

5.14.3 Using the standard self diagnostics of Standard Industrial Commercial Products will perform these functions at the server, microprocessor and network level and display results.

5.14.4 Using the standard self diagnostics of Standard Industrial Commercial Products will perform these functions at the server, microprocessor and network level and display results. Special test scripts will not be provided.

5.14.5 Using the standard self diagnostics of Standard Industrial Commercial Products will perform these functions at the server, microprocessor and network level and display results. Special test scripts will not be provided.

5.14.6 Indications of faults will be clearly displayed at the CAD station.

6.0 SYSTEM INTERFACE AND FUNCTIONS

6.1 General

6.1.1 The CAD system will interface with the Hanford Patrol and the Hanford Fire Department. It will receive information from the protected area alarm system (secondary alarms), direct reporting local alarms, phone and radio. It will also receive actual fire alarms from the Hanford Fire Department serial data streams. It will have the capability to dispatch by radio or telephone. It will also interface with the Benton County Sheriff's office, and Washington Central Computerized Enforcement Services System. Previous described equipment and software is what is expected of the CAD system and the following describes the interface requirements. Requirements may 
be duplicated in previous sections. The following information is an aid to the Seller.

This functionality provides the secondary reporting and annunciation of protected area (PFP) alarms and the secondary annunciation (courtesy) of fire alarms.

6.2.1.1 Alarms will be annunciated by an audible tone and flashing light on the CAD station console when an alarm is received by the system.

6.2.1.2 General information will be displayed at the CAD station and critical information will be displayed on the AP Supervisor for appropriate actions. The information will be presented in the following forms:

- Textual-Display of alarm information (type, location, condition).

- Instructions-Special instructions, such as for hazards and exposures, are provided for critical areas.

6.2.1.3 System activities will be logged to a hard copy device for historical reference. The information logged will include the following:

6.2.1.3.1 Date / Time.

6.2.1.3.2 Alarm Type (tamper, open, short, alarm, normal).

6.2.1.3.3 Alarm Class (security, fire, criticality).

6.2.1.3.4 Sensor Type (microwave, infrared).

6.2.1.3.5 Sensor Location (door number).

6.2.1.3.6 Zone Description (facility area).

6.2.1.3.7 Operator actions-Transactions made to acknowledge, assess, and dispose of the alarms.

6.2.1.4 System activities will be logged to a disk file. The file will be transferred to removable media on a periodic basis for analysis and long-term storage. NOTE: Archival files contain both secondary protected area alarms, local alarms, and fire alarm system activity information. 
6.2.1.5 The system monitors the health of the network communications and the connected systems. Symbols represent connected systems. Symbol colors represent operational status loperational, standby, inoperable).

6.2.2 Local/Industrial Security Alarm Monitoring Function

6.2.2.1 The function is to provide a monitoring point for alarms outside the boundaries of the protected areas (PFP).

6.2.2.2 Alarms will be annunciated by an audible tone and flashing light when an alarm is received by the system.

6.2.2.3 Critical information will be displayed to the dispatcher for appropriate actions. The information will be presented in the following forms:

6.2.2.3.1 Textual - Display of alarm information (type, location, condition).

6.2.2.3.2 Graphical - Display a map of the area where the alarm occurred.

6.2.2.4 System activities will be logged to both a hard copy device and to a disk file for historical reference. The information logged includes the following:

\subsection{Date / Time.}

6.2.2.4.2 Alarm Type (tamper, open, short, alarm, normal).

6.2.2.4.3 Alarm Class (security, fire, criticality).

6.2.2.4.4 Sensor Type (microwave, infrared).

6.2.2.4.5 Sensor Location (door number).

6.2.2.4.6 Zone Description (facility area).

6.2.2.4.7 Operator Log-On.

6.2.2.4.8 Sensor Mode Changes.

6.2.2.4.9 Transactions made to acknowledge, assess, and dispose of the alarms.

6.2.2.5 The system will be capable of generating reports to a printer. The reports include the following:

6.2.2.5.1 All Sensors - List of all sensors in the system and their 
WHC-SD-L251-SDS-001

Rev. 1

Page 53

current status (mode and state).

6.2.2.5.2 Inactive Sensor

6.2.2.5.3 Access Sensor

6.2.2.5.4 All Zones

6.2.2.5.5 Single Zone

6.2.2.5.6 Single Access

6.2.2.5.7 All Access Set

6.2.2.5.8 Event Sensor
List of sensors in the inactive mode and their current state (alarm, open, short, tamper, normal).

- List of sensors in the access mode and their current state (alarm, open, short, tamper, normal).

- List of sensors per zone (facility area) and description of each zone.

- List of sensors for a particular zone (facility area) and description of the zone.

- List of sensors that can be placed in an access Set mode as a group.

- List of groups of sensors that can be placed into an access mode.

- List of sensors that generated the specified security event.

6.2.2.5.9 Sensor Verification Information as to the condition of a particular sensor.

6.2.2.6 The system will be capable of modifying the modes of the sensors. The sensor modes will include the following:

6.2.2.6.1 Secure

6.2.2.6.2 Access

6.2.2.6.3 Inactive
- All sensor state changes are reported. State changes include "alarm," "tamper," "open," "short," and "normal."

- Sensor "alarms" are filtered; "tamper," "normal," "open," and "short" are reported.

- No sensor state changes are reported.

6.2.2.7 The system will be capable of displaying sensor modes and states in real time. The information will be displayed in the following forms:

\subsection{Sensor Status}

A matrix of sensors symbols with colors and Map characters that represent the modes and states of the sensors. 
6.2.2.7.2 Graphics Map - Facility area maps containing symbols that represent the modes and states of the sensors.

6.2.2.8 The system will monitor hardware and software health and report problems. The system health tests will be performed on the following:

6.2.2.8.1 Dispatch and servers.

6.2.2.8.2 Peripheral equipment.

6.2.2.8.3 Programs.

6.2.3 Communications System. The POC uses radio and telephone equipment to receive site emergency calls and direct response forces. Communications will be recorded for legal and historical reference.

Law Enforcement Radio Network. This network is used by the POC to communicate with law enforcement agencies outside the Hanford site.

Washington Central Computerized Enforcement Service System. The primary function is to provide the Benton County Sheriff's Department with information such as driver's license and vehicle registration checks, as well as wants or warrants. This system also provides for interagency communications.

6.2.6 Duress Monitoring System. The primary function is to identify patrol, fire, or important persons that are in duress.

Aircraft Communication System. This function of this system is to communicate with aircraft in the vicinity of the Hanford Site.

Telecommunication Alarm and Control System. The primary function of this system is to monitor alarms on the telecommunications equipment. This system also allows patrol to switch the radio repeater transceivers from Gable Mountain to Rattlesnake Mountain. This allows complete radio communication coverage for the Hanford Site.

6.2.9 Encrypted Telephone System. The primary function of this system is to allow classified or sensitive communications with other agencies.

6.2.10 The expected inputs to the new CAD system are:

6.2.10.1 Of the alarms coming into POC, there are about 500 security sensors that currently report to the MUX which will be converted to contact closure type inputs to the new system. These inputs may be either a single contact closure reporting only alarm/reset conditions; or, a dual 
WHC-SD-L251-SDS-001

Rev. 1

Page 55

contact closure reporting alarm/reset and tamper/reset conditions.

6.2.10.2 The 500 fire alarms that come into POC arrive as data streams on a RS-232 data line (300 BPS), not as contact closures. Three (3) message types are received from CFS system:

1) CFS Restart: Send $80 \mathrm{~h}$; response none; action, counts as a heartbeat message.

2) CFS Heartbeat: Sends $81 \mathrm{~h}$; response none; action, restart heartbeat fail timers. If heartbeat fail timer reaches some parametric value, the system will notify the operator of a loss of communication with CFS.

3) CFS Actual Fire Alarm with Dispatch: Sends 5-byte message beginning with $4 w h, x, y, z, 0 ; 4 w h$ indicates the alarm subtype, where $w$ may be 2 through $B$, current understanding shows that the message subtype sent and received is $4 \mathrm{Bh}$ indicating an actual fire alarm and that message subtype $42 \mathrm{~h}$ through $4 \mathrm{Ah}$ are not sent.

The $x y, z$ parameters represent information about the origin of the fire alarm box from which the alarm was received. Information on decoding these values will follow at a later date.

Response none; action, decode message and annunciate a fire alarm notification to the operator.

4) Any other messages are to be ignored.

6.2.10.3

The inputs to POC from PFP for redundant alarm reporting will arrive at POC as data streams on a RS-232 data line (different form the incoming fire alarm data stream). The system at PFP will be a Graphic Link system from Scientific Approaches. The CAD system will communicate with the PFP Graphic Link system. The format for the PFP Graphic Link messages and required responses will be provided by the Buyer.

6.2 .10 .4

A RS-232 data port will be provided for an interface to an industrial/video alarm system. The CAD system will be capable of communicating, through this port, with dedicated equipment for remote site monitoring. 
WHC-SD-L251-SDS-001

Rev. 1

Page 56

6.3

6.3 .1

6.3 .2

6.3.2.2

6.3.2.3 Time.

6.3 .2 .4

6.3.2.5

6.3 .3

6.3 .4

6.3 .6

Date.

\section{Future Fire Alarm Operations}

The main purpose of a Radio Fire Alarm Reporting (RFAR) System is to receive and record fire related alarms. The system will be located in the Hanford Emergency Alarm Dispatch System Facility and at each of the outlying fire stations $(100,200,300$, and 400 Areas). The functions provided by the RFAR System are described in the following sections.

The RFAR receiving system will be supplied by the G. H. Harlow Company, P. O. Box 185, Lake Oswego, Oregon 97034. G. H. Harlow Company will be contacted so the appropriate interfacing equipment and software will be supplied between the RFAR receiver and the CAD stations.

Radio fire alarm boxes, located in buildings around the Hanford Site are monitored for fire and trouble alarm messages. The 30 bit alarm messages are decoded into textual messages containing the following information:

Alarm type.

Box identification.

The decoded messages are transmitted to the Computer Aided Dispatch (CAD) System for further processing.

Decoded fire and trouble alarm messages are displayed to the dispatch operator for appropriate actions.

Decoded fire and trouble alarm messages are recorded to a hard copy device as a permanent record of alarm activity.

The CAD System will upon receipt of a trouble or fire alarm activate an audible tone and flashing light. The audible tone is different for a trouble or a fire alarm.

Radio fire alarm box check-in messages are received for the purpose of recording, which boxes remain functional. Each fire alarm box is individually programmed to send its check-in message at a specified time (once per day). 
WHC-SD-L251-SDS-001

Rev. 1

Page 57

6.3.7 The AP supervisor will receive fire and trouble alarm signals from the RFAR System and provides the dispatcher with critical information about the alarm. The critical information consists of the following:

6.3.7.1

6.3.7.2

6.3.7.3

6.3.7.4

6.3.7.5

6.3.7.6

6.3.7.7

6.3.7.8

6.3.7.9

6.3.7.10

6.3.7.11

6.3.7.12

6.3 .8

6.3 .8 .1

6.3.8.2

6.3.8.3

6.3.8.4

A link status is visually displayed in the AP supervisor to the operator in the form of a colored symbol. The color is updated in real time when the status changes. The color green represents that the link is 
WHC-SD-L251-SDS-001

Rev. 1

Page 58

operational, while red represents that the link is inoperable. The color blue represents that communication was never established.

6.3 .8 .5

The AP supervisor will be capable of controlling the reporting of alarms by box or zone from the RFAR System. The statuses that a box or zone can be in are as follows:

6.3.8.5.1

BYPASS

-Alarms are ignored by the system. Alarms can be bypassed for an individual fire zone, for trouble alarms only, for all fire zones and trouble alarms, or for the front button alarm on the transmitter.

6.3.8.5.2

ACTIVE

- All alarms for a box or zone are reported by the system.

6.3.8.5.3

CARRY-OVER (C-O) -

Label used to document long-term alarm system impairments. All alarms will report and annunciate.

6.3.8.5.4

TROUBLE

- Label used to document short-term alarm system problems. All alarms will report and annunciate.

6.3.8.6

The CAD System will maintain a data base of information on the equipment (vehicles) used for emergency responses. The data base includes the following:

6.3.8.6.1 Equipment identification.

6.3.8.6.2 Equipment location.

6.3.8.6.3 Equipment status (in service, out of service, responding, on scene).

6.3.8.6.4 Assigned backup.

6.3.8.6.5 Comments (i.e., condition of equipment).

6.3.8.6.6 The CAD System will allow for the Adding, Deleting, and Changing of any record in the data base, with the access level of the user determining what he/she is able to perform.

6.3.8.7 Maintain Building Data Base. The CAD System will maintain a data base of Hanford building information. The CAD system will be capable of reading this building information from any AutoCAD Release 12 database. The data base includes the following:

6.3.8.7.1 Radio fire alarm box number.

6.3.8.7.2 Building identification.

6.3.8.7.3 Fire zone(s).

6.3.8.7.4 Fire alarm boxes. 
Rev. 1

Page 59
6.3.8.7.5
Hazards.
6.3.8.7.6
Exposures (adjacent structures that may be threatened).
6.3.8.7.7
6.3 .8 .7 .8
Special exposures (i.e., propane tank).
6.3.8.7.9
6.3.8.7.10
Notes (comments).
Building graphics (floor plan).
Radiation hazards.

6.3.8.8 The CAD System will be capable of displaying reports to the screen or printing to a hard copy device. The reports available on the CAD System will be as follows:

6.3.8.8.1 Alarm - Reports alarms received for a specified date and time.

6.3.8.8.2 Equipment - Reports a list of all equipment and the current status of the equipment.

6.3.8.8.3 User - Reports a list of users entered into the system.

6.3.8.8.4 Building - Reports a list of buildings and the boxes and zones associated with those buildings. It also shows if a graphic (floor plan) exists for a particular zone.

6.3.8. 8.5

Alarm Status - Reports a list of boxes and their status changes for a specified time period. If time period is not within the current $\log$ archive file then the appropriate floppy disk must be inserted into the $A$ drive. The report is printed in box order. Typical time period of this report is the last 24 hours.

6.3.8.8.6 Alarm Carryover - Reports a list of all boxes currently on the alarm status list, including those carried over from previous time periods.

6.3.8.8.7 Field Incident - Reports a list of all Field Incident Reports (FIR) stored in the system.

6.3.8.9 The CAD System will have the capability to send and receive electronic mail messages to any other station or to a vehicle equipped with a Mobile Display Terminal (MDT). Sending a message to all stations and vehicles equipped with MDTs is also possible. The operator is notified upon receipt of mail messages both visually and with an audible tone.

6.3.8.10 The CAD System will provide data protection through assignment of user authorization levels. The user is given capabilities equivalent to the authorization level at the time of logging onto the system. 
6.3.8.11 The System Control functions will be as follows:

6.3.8.11.1 Network Node - Allows the user to configure the eight set up communication ports and to assign the MDT units to the fire apparatus.

6.3.8.11.2 Control Port

6.3.8.11.3 Graphics Update
- Allows the user to activate or deactivate the Setup ability to raise doors, turn on lights, etc., in the outlying stations.

Allows graphics to be updated from a floppy disk without exiting the program. Will only update the graphic if the appropriate building/zone exists in the data base.

6.3.8.11.4 Exit - Allows the user to exit from the program.

6.4 Radio Circuit Functions

6.4.1 The radio controllers/remotes are connected to the existing radios via leased telephone lines or other voice grade circuits. Each RCL circuit has the following functional parameters:

6.4.1.1 Circuit Type: The circuit has either a 2-wire or 4-wire voice requirement.

6.4.1.2 Frequency: The circuit is designated with Frequency $1(\mathrm{~F}-1)$ or Frequency $2(\mathrm{~F}-2)$.

6.4.1.3 Transmit Control: The circuit will use DC $(F-1+6.5$ ma or F-2 +12 $\mathrm{mal}$ or tones to control the transmit function.

6.4.1.4 Impedance: $600 \mathrm{ohm}$ impedance (input and output) transformer isolated.

6.4.1.5 Talk Power: The normal voice levels are $0 \mathrm{dBm}$ (adjustable -20 to plus $10 \mathrm{dBm}$ ) for both transmit and receive paths.

6.4.1.6 Proprietary Signaling Format: Some channels use proprietary and coded signaling format.

1) Duress system channels require Duress Decode and Unit ID Decoder capability. Two proprietary duress alarm systems are used in tandem.

a) System 1: A Motorola MDC-600 (to be upgraded to a MDC-1200) decoder provides a visual display, audible 
WHC-SD-L251-SDS-001

Rev. 1

Page 61

duress alarm and a RS-232C serial interface for a printer (selectable $300,1200,9600$ or 76,800 bits per second).

Known signaling characteristics are:

- Modulation. Phase Shift Keying (PSK) modulation and demodulation.

- Data Rate. 600 bits per second (bps).

- Carrier Frequency. $1500 \mathrm{~Hz}$.

- Packet Size. Data is transferred in bursts $290 \mathrm{~ms}$ in duration.

b) System 2. A General Electric/Coded Communications Model MBD-5U uses the G-Star format. The decoder provides visual display, audible duress alarm and RS-232C serial interface for a printer at 110 or 300 bps. Known signaling characteristics are:

- Modulation. PSK modulation and demodulation.

- Data Rate. 400 bps.

- Carrier Frequency. $1600 \mathrm{~Hz}$.

6.4.1.7 Signaling. Channel signaling is performed by current or tone for the selected functions. The most common function being Push-To-Talk (PTT) and frequency selection of a selected transmitter. The tones used are common industry standard tone format. The sequence when the PTT is pushed consists of a high level guard or "wake-up" tone, then a function tone, followed by a low-level PTT tone. The specific tone signaling is shown in Table I. All radios will eventually be tone controlled in the future.

Table I - PTT Signaling

\begin{tabular}{|l|c|c|c||}
\hline \multicolumn{1}{|c|}{ Tone } & $\begin{array}{c}\text { Frequency } \\
(\mathrm{Hz})\end{array}$ & $\begin{array}{c}\text { Duration } \\
(\mathrm{ms})\end{array}$ & $\begin{array}{c}\text { Power } \\
(\mathrm{dBm})\end{array}$ \\
\hline Guard (Wake Up) & 2175 & 130 & +10 \\
\hline Function & $\begin{array}{c}1950(\mathrm{~F}-1) \\
1850(\mathrm{~F}-1)\end{array}$ & 40 & 0 \\
\hline PTT & 2175 & continuous & -20 plus voice \\
\hline
\end{tabular}


WHC-SD-L251-SDS-001

Rev. 1

Page 62

6.4.1.8 Supervisory Alarm/System (BRAMCO). This alarm system provides remote switching and alarm/status reporting of 20 contacts each at two remote locations. The known BRAMCO operating parameters are:

1) Circuit Type. Voice grade 4 wire telephone circuit.

2) Modulation. Frequency shift keying (FSK) tones of $660 \mathrm{~Hz}$ to Transmit, and $1020 \mathrm{~Hz}$ and $900 \mathrm{~Hz}$ to receive.

3) Coding. The coding technique is a 21 pulse binary word (20 functions plus parity), double scanned.

6.4.1.9 Alert Tone Generation.

6.4.2 Specific Functional Circuit Requirements

6.4.2.1 Twenty-one radio channels shall be connected to the control consoles. The specific circuit requirements are listed in Table II. Expansion capability is required to at least 24 channels. 
WHC-SD-L251-SDS-001

Rev. 1

Page 63

Table II - Specific Radio Channels

\begin{tabular}{|c|c|c|c|c|c|c|}
\hline Ckt No. & Assigned To: & Type & Signal & Freq. & Duress? & Notes \\
\hline KKE-624 & Patrol & $4 W$ & Tone & $\begin{array}{l}F-1 \\
F-2\end{array}$ & Yes & $F-2$ is DES \\
\hline KFW-660 & Fire & $2 W$ & DC & $F-1$ & & \\
\hline KOK-219 & TAC3 (local) & $4 W$ & Tone & $\begin{array}{l}F-1 \\
F-2\end{array}$ & Yes & $F-2$ is DES \\
\hline KOK-219 & TAC3 (South) & $2 \mathrm{~W}$ & Tone & $\mathrm{F}-1$ & Yes & \\
\hline KOK-219 & TAC3 (RSB) & $2 \mathrm{~W}$ & Tone & $\mathrm{F}-1$ & Yes & \\
\hline KOK-219 & $\begin{array}{l}\text { TAC3 (405- } \\
\text { CON) }\end{array}$ & $2 W$ & Tone & $F-1$ & Yes & \\
\hline KOK-219 & TAC3 (4621-E) & $2 W$ & Tone & $\mathrm{F}-1$ & Yes & \\
\hline KOK-219 & TAC3 (Fed) & $2 W$ & Tone & $F-1$ & Yes & \\
\hline KOK-219 & TAC3 (North) & $2 W$ & Tone & $F-1$ & Yes & \\
\hline KOB-743 & Safety & $2 \mathrm{~W}$ & DC & $F-1$ & & \\
\hline KRF-249 & $\begin{array}{l}\text { Transport- } \\
\text { ation }\end{array}$ & $2 W$ & DC & $F-1$ & Yes & \\
\hline KMD-88 & Coast Guard & $2 W$ & $D C$ & $\begin{array}{l}F-1 \\
F-2\end{array}$ & & \\
\hline KHA-320 & LERN & $2 W$ & $D C$ & $\mathrm{~F}-1$ & & \\
\hline KOM-785 & Super LERN & $4 W$ & Tone & $\mathrm{F}-1$ & & \\
\hline KDC-574 & BC Sheriff & $2 W$ & $D C$ & $\mathrm{~F}-1$ & & \\
\hline$K Z I-509$ & WPPSS & $2 W$ & Tone & $\mathrm{F}-1$ & & \\
\hline KOE- 649 & Fire TAC & $2 W$ & Tone & $\mathrm{F}-1$ & & To be added \\
\hline KKG-290 & BCFPD \#1 & $2 W$ & Tone & $F-1$ & & To be added \\
\hline KOO-9 & Aircraft & & & & & $\begin{array}{l}\text { Local control only } \\
\text { for multiple } \\
\text { frequency use }\end{array}$ \\
\hline $\mathrm{KGH}-513$ & Tank Farms & $2 W$ & Tone & $\mathrm{F}-1$ & & To be added \\
\hline KKE-625 & Trunked Radio & $2 W$ & Tone & $\begin{array}{l}F-1 \text { thru F- } \\
5\end{array}$ & & $\begin{array}{l}\text { Requires additional } \\
\text { control tones: } \\
1350 \mathrm{~Hz}(\mathrm{~F}-3) \\
1250 \mathrm{~Hz}(\mathrm{~F}-4) \\
1050 \mathrm{~Hz}(\mathrm{~F}-5)\end{array}$ \\
\hline
\end{tabular}

$2 W=$ Two-wire voice grade

$4 \mathrm{~W}=$ Four-wire voice grade

$D C=$ Direct current voltage signaling

DES $=$ Data Encryption Standard

$\mathrm{F}-1=$ Frequency 1

$\mathrm{F}-2=$ Frequency 2

END OF SECTION

W:8522S048.GTE

081596 


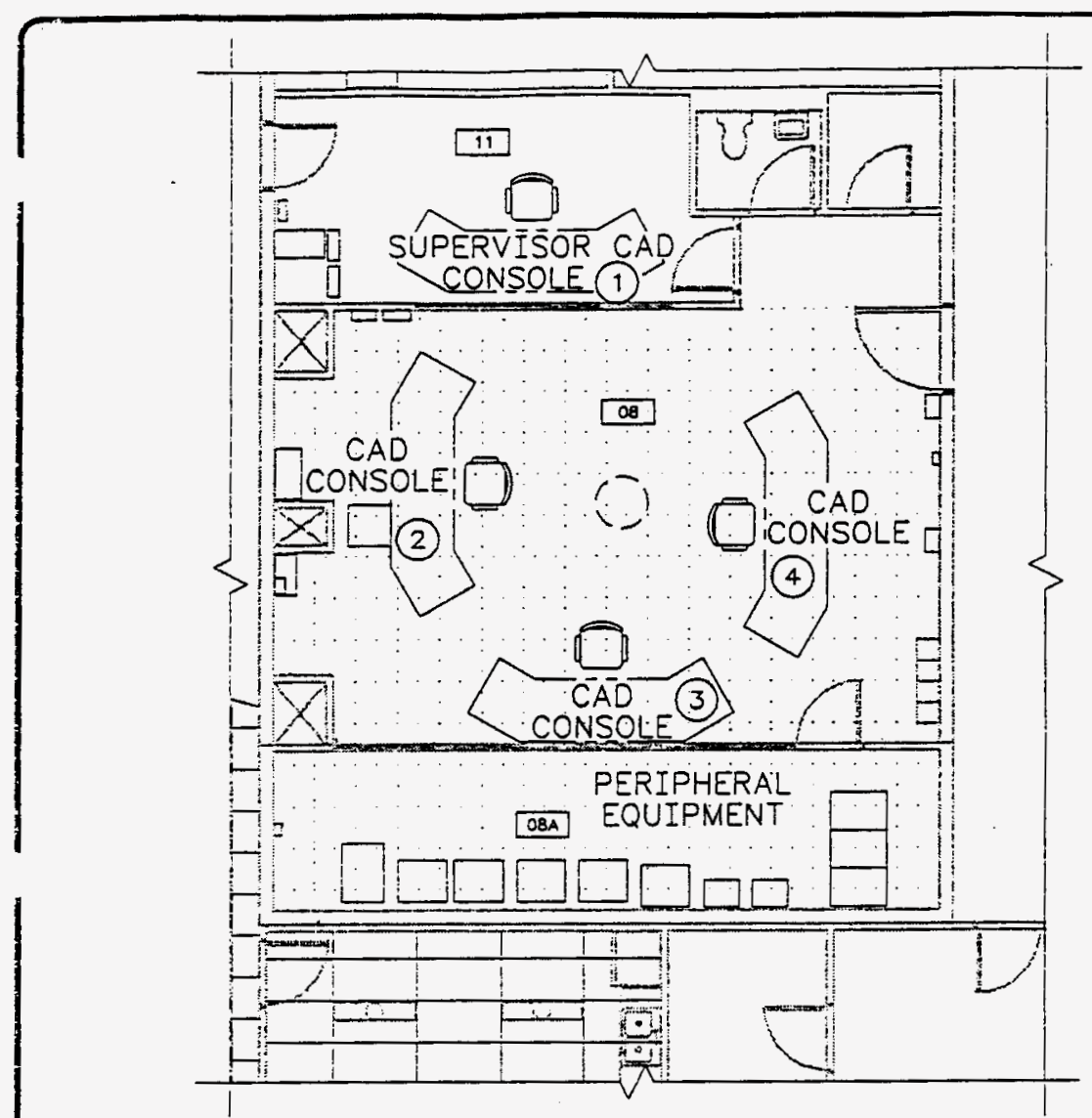

\section{$\frac{\text { PARTIAL PLAN }-2721 \mathrm{E} \quad \text { BLDG }}{\text { SCALE: }{ }^{\prime \prime}=1^{1}-0^{\prime \prime}}$}

NOTE

THIS IS A SUGGESTED LAYOUT FOR THE CAD CONSOLES FOR THE HANFORD EMERGENCY ALARM DISPATCH SYSTEM.

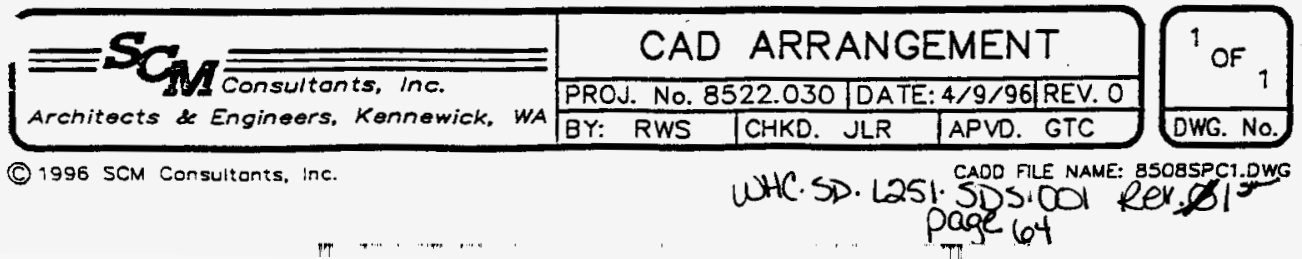




\begin{tabular}{|c|c|c|c|c|c|}
\hline \multicolumn{6}{|c|}{ DISTRIBUTION SHEET } \\
\hline \multirow{2}{*}{$\begin{array}{l}\text { To } \\
\text { Distribution }\end{array}$} & \multirow{2}{*}{$\begin{array}{l}\text { From } \\
\text { MG Briggs }\end{array}$} & & & \multicolumn{2}{|l|}{ Page 1 of 1} \\
\hline & & & & \multicolumn{2}{|c|}{ Date $09 / 30 / 96$} \\
\hline \multirow{2}{*}{\multicolumn{4}{|c|}{$\begin{array}{l}\text { Project Title/Work Order } \\
\text { Hanford Emergency Alarm Dispatch System/L-251/C18760 }\end{array}$}} & \multirow{2}{*}{\multicolumn{2}{|c|}{$\begin{array}{l}\text { EDT No. } \\
\text { ECN No. L251-006 } \\
\end{array}$}} \\
\hline & & & & & \\
\hline Name & MSIN & $\begin{array}{c}\text { Text } \\
\text { With } \\
\text { All } \\
\text { Attach } \\
\text {. } \\
\end{array}$ & $\begin{array}{l}\text { Text } \\
\text { Oniy }\end{array}$ & $\begin{array}{c}\text { Attach. } \\
/ \\
\text { Appendi } \\
x \\
\text { Only }\end{array}$ & $\begin{array}{l}\text { EDT/ECN } \\
\text { Only }\end{array}$ \\
\hline $\begin{array}{l}\text { MG Briggs } \\
\text { LE Cyr } \\
\text { DS Davis } \\
\text { TJ Hubbard } \\
\text { Central Files (Original) } \\
\text { Document Service Center } \\
\text { SCM Associates } \\
\text { GTE }\end{array}$ & $\begin{array}{l}\text { G3-08 } \\
\text { S2-98 } \\
\text { S2-46 } \\
\text { S2-53 } \\
\text { A3-89 } \\
\text { G3-11 } \\
\text { G3-08 } \\
\text { G3-08 }\end{array}$ & $\begin{array}{l}1 \\
1 \\
1 \\
2 \\
1 \\
1 \\
2 \\
2\end{array}$ & & & \\
\hline
\end{tabular}

